\title{
Structural Reversibility and Nickel Particle stability in Lanthanum Iron Nickel Perovskite-Type Catalysts
}

\author{
Patrick Steiger, ${ }^{[\mathrm{a}, \mathrm{b}]}$ Renaud Delmelle, ${ }^{[\mathrm{c}]}$ Debora Foppiano, ${ }^{[\mathrm{a}, \mathrm{d}]}{ }^{\left[{ }^{2}\right.}$ orenz Holzer, ${ }^{[\mathrm{e}]}$ Andre Heel, ${ }^{[\mathrm{c}]}$ \\ Maarten Nachtegaal, ${ }^{[a]}$ Oliver Kröcher, ${ }^{[a, b]}$ and Davide Ferri ${ }^{[a]}$
}

Perovskite-type oxides have shown the ability to reversibly
segregate precious metals from their structure. This reversible
segregation behavior was explored for a commonly used cata-
lyst metal, $\mathrm{Ni}$, to prevent $\mathrm{Ni}$ sintering, which is observed on
most catalyst support materials. Temperature-programmed re-
duction, $\mathrm{X}$-ray diffraction, $\mathrm{X}$-ray absorption spectroscopy, elec-
tron microscopy, and catalytic activity tests were used to
follow the extent of reversible $\mathrm{Ni}$ segregation. LaFe ${ }_{1-x} \mathrm{Ni}_{x} \mathrm{O}_{3 \pm \delta}$
$(0 \leq x \leq 0.2)$ was synthesized using a citrate-based solution pro-

cess. After reduction at $600^{\circ} \mathrm{C}$, metallic Ni particles were displayed on the perovskite surfaces, which were active towards the hydrogenation of $\mathrm{CO}_{2}$. The overall $\mathrm{Ni}$ reducibility was proportional to the $\mathrm{Ni}$ content and increased from $35 \%$ for $x=$ 0.05 to $50 \%$ for $x=0.2$. Furthermore, Ni could be reincorporated reversibly into the perovskite lattice during reoxidation at $650^{\circ} \mathrm{C}$. This could be exploited for catalyst regeneration under conditions under which impregnated materials such as $\mathrm{Ni}$ / $\mathrm{LaFeO}_{3 \pm \delta}$ and $\mathrm{Ni} / \mathrm{Al}_{2} \mathrm{O}_{3}$ suffer from sintering.

\section{Introduction}

Perovskite-type metal oxides (PMOs) represent a class of mixed oxides with important catalytic properties. ${ }^{[1,2]}$ Although PMOs can be used as catalysts without further doping, they can also serve as supports for catalytically active metal phases. The interface generated between the PMO and the metal nanoparticles is of similar nature to that between reducible metal oxides and metals and shows comparable properties. Contrary to other metal oxides, it has been demonstrated that precious metals (Pd, Rh, Pt) can be segregated reversibly from PMO lattices that, under fluctuating redox reaction conditions such as those encountered in automotive exhaust gas streams. This

[a] P. Steiger, D. Foppiano, Dr. M. Nachtegaal, Prof. O. Kröcher, Dr. D. Ferri Paul Scherrer Institut

5232 Villigen PSI (Switzerland)

E-mail: davide.ferri@psi.ch

[b] P. Steiger, Prof. O. Kröcher

Institute of Chemical Sciences and Engineering

École polytechnique fédérale de Lausanne (EFPL)

1015 Lausanne (Switzerland)

[c] Dr. R. Delmelle, Dr. A. Heel

IMPE_-Institute for Materials and Process Engineering

Zurich University of Applied Sciences

8400 Winterthur (Switzerland)

[d] D. Foppiano

Institute of Environmental Engineering

École polytechnique fédérale de Lausanne (EPFL)

1015 Lausanne (Switzerland)

[e] Dr. L. Holzer

ICP-Institute of Computational Physics

Zurich University of Applied Sciences

8400 Winterthur (Switzerland)

(D)

Supporting Information and the ORCID identification number(s) for the

iD author(s) of this article can be found under https://doi.org/10.1002/ cssc. 201700358. temperature-limited process $^{[3]}$ improves the resistance against precious metal sintering significantly. ${ }^{[4,5]}$ Analysis by X-ray photoelectron spectroscopy (XPS) and X-ray absorption near edge spectroscopy (XANES) after isothermal reduction and oxidation treatments at increasing temperatures showed that the fraction of Pd adopting the coordination of the B-site element and segregating at the PMO surface upon reduction and the fraction of $\mathrm{Pd}^{0}$ dissolving in the PMO lattice upon oxidation increases with increasing temperature. Several simulations have been attempted to explain this process. ${ }^{[6]}$ However, likely not all of the reduced metal is actually accessible for catalysis. ${ }^{[7]}$ The propensity of metals to be stabilized in high oxidation states within PMO lattices and thus to be ideally suited to undergo self-regeneration also depends on the PMO composition $^{[8]}$ and synthesis method. ${ }^{[9]} \mathrm{A}$ major advantage of this approach is that the precious metal content can be reduced significantly without compromising activity and stability. ${ }^{[10-12]}$

We are interested in exploring this peculiar property of PMOs for cheaper and more abundant metals that can be potentially used as catalysts and have thus started to investigate $\mathrm{Ni}$. As a result of its high activity, selectivity, and cost efficiency, low-cost $\mathrm{Ni}$, dispersed on various types of supports, is the predominant active phase of choice in catalytic reactions involved in industrial power-to-gas processes such as the dry and wet reforming of hydrocarbons, ${ }^{[13-16]}$ combined reforming of methane with $\mathrm{CO}_{2}$ and $\mathrm{O}_{2}$, ${ }^{[17]}$ water-gas shift, ${ }^{[16]}$ hydrogenation of carbon oxides, ${ }^{[18-21]}$ and Fischer-Tropsch reaction. ${ }^{[22]}$ However, these catalysts can be subjected to severe operation conditions because of the exothermicity of $\mathrm{CO}$ and $\mathrm{CO}_{2}$ hydrogenation reactions ${ }^{[16]}$ or to the high process temperatures of reforming reactions that make $\mathrm{Ni}$ particle sintering a common deactivation mechanism. ${ }^{[23]}$ In an effort to minimize the deacti- 
vation rate of supported $\mathrm{Ni}$ nanoparticle catalysts, common strategies focus on careful low-temperature regeneration, ${ }^{[24,25]}$ the increase of the sintering resistance of the catalyst through alloying ${ }^{[26]}$ confinement, and encapsulation of metal particles $^{[27,28]}$ and strong metal-support interactions. ${ }^{[29]}$ To this end, PMOs have been proposed as precursors to generate active supported $\mathrm{Ni}$ catalysts. The high-temperature reduction of $\mathrm{LaNiO}_{3 \pm \delta}$ generates $\mathrm{Ni}$ particles on $\mathrm{La}_{2} \mathrm{O}_{3}$ that are better than conventional $\mathrm{Ni}$-based catalysts at the same temperature in terms of $\mathrm{Ni}$ dispersion and catalytic activity. ${ }^{[30,31]}$ If $\mathrm{Ni}$ is incorporated inside the PMO lattice by partial substitution of the Bsite element, it can segregate upon reduction to form catalytically active particles. ${ }^{[32-34]}$ The strong adhesion of these particles to the support surface was found to be strongly beneficial in terms of coking resistance. ${ }^{[35,36]}$ Conversely, the self-regenerating properties of PMOs demonstrated for precious metals have been scarcely studied with $\mathrm{Ni}$. Recent findings suggest that this self-regeneration behavior can also be applied to $\mathrm{Ni}$ perovskites, at least for high-temperature processes. ${ }^{[17,37,38]}$ We have shown that a careful selection of the PMO composition produces suitable anodes for solid oxide fuel cells with the capability to segregate and reincorporate $\mathrm{Ni}$ at relevant temperatures $\left(>800^{\circ} \mathrm{C}\right)$. Deng et al. reported a sintering-resistant La-PrFe-Ni-O methane oxidative reforming catalyst that demonstrates a redox reversible segregation-incorporation process at $700^{\circ} \mathrm{C}$, which was not fully reversible at the investigated temperatures. ${ }^{[17]}$

Through the self-regenerating property, PMOs have the potential to overcome sintering issues observed during operation and oxidative regeneration of $\mathrm{Ni}$ catalysts. Hence, in this work we attempt to rationalize the necessary parameters to induce complete structural reversibility in this type of materials using a probe reaction, which is catalyzed by $\mathrm{Ni}$, that is, $\mathrm{CO}_{2}$ hydrogenation. X-ray diffraction, temperature-programmed reduction and oxidation, and X-ray absorption spectroscopy are used to characterize the extent of reversible Ni segregation.

\section{Results and Discussion}

The results of the elemental analysis obtained by using inductively coupled plasma-mass spectrometry (ICP-MS), the specific surface area (SSA) of the calcined powders, as well as sample denotations are reported in Table 1 together with the sample notation. The SSA of the calcined powders was not affected by the $\mathrm{Ni}$ content and was in the range of $11-13 \mathrm{~m}^{2} \mathrm{~g}^{-1}$ in agreement with reported values for comparable material compositions prepared by similar methods. ${ }^{[17,39-42]}$

The XRD patterns of LFO, LFNO-5Ni, LFNO-20Ni, and the impregnated samples LFO-5Ni and LFO-20Ni before and after each step of a redox cycle match the orthorhombic $\mathrm{LaFeO}_{3 \pm \delta}$ structure (space group Pnma), which suggests that the incorporation of small amounts of $\mathrm{Ni}$ had no effect on the lattice symmetry (Figure S1 a-c in the Supporting Information). The $2 \theta$ ranges of $30.5-33,42-45$, and $28-31^{\circ}$ are magnified in Figure 1 to emphasize the position of the main $\mathrm{LaFeO}_{3}$ (121) reflection, the presence of the (221) reflection, and the absence of the $\mathrm{NiO}(200)$ and $\mathrm{La}_{2} \mathrm{O}_{3}(101)$ reflections for all but the impregnated samples. The absence of the $\mathrm{NiO}$ and $\mathrm{La}_{2} \mathrm{O}_{3}$ reflections in the calcined LFNO-type powders (Figure $1 \mathrm{~b}$ and c) indicates the complete incorporation of $\mathrm{Ni}$ into the perovskite lattice. We assign an oxidation state $n>2+\left(\mathrm{Ni}^{n+}{ }_{\text {oct }}\right)$ to this species for the sake of the simplicity of discussion (vide infra). This will become clear in the following paragraphs. The homogeneous distribution of $\mathrm{Ni}$ within the perovskite lattice is also demonstrated by the linear shift of the $\mathrm{LaFeO}_{3}(121)$ reflection towards higher $2 \theta$ values with increasing $\mathrm{Ni}$ content (Figure $1 \mathrm{a}$ ). The shift corresponds to the formation of a solid solution between $\mathrm{LaFeO}_{3 \pm \delta}$ and $\mathrm{LaNiO}_{3 \pm \delta}$ and, therefore, a linear apparent contraction of the unit cell with increasing $\mathrm{Ni}$ content. ${ }^{[43]}$ As the ionic radius of $\mathrm{Ni}^{3+}(0.60 \AA)$ in octahedral coordination is slightly smaller than that of $\mathrm{Fe}^{3+}(0.645 \AA)$ in the same coordination environment, ${ }_{r}^{[44]}$ the substitution of $\mathrm{Fe}$ by $\mathrm{Ni}$ inside the perovskite lattice is responsible for the decrease in the unit cell dimensions. However, an increase of the substitution of Fe with $\mathrm{Ni}$ was also reported to enhance oxygen vacancy formation, leading to nominally lower charged B-site cations of a larger size, which could result in the opposite effect, that is, an increase in the unit cell volume. ${ }^{[45]}$ As the trend of the experimental XRD data resembled the decrease of the unit cell volume with increasing $\mathrm{Ni}$ concentration, we consider that the former effect dominated for the compositions studied in this work.

$\mathrm{LaFe}_{1-x} \mathrm{Ni}_{x} \mathrm{O}_{3 \pm \delta}$ compositions with higher Fe substitution ( $x=$ $0.40,0.60,0.80,1.00$ ) were also synthesized and evaluated for their use as structurally reversible $\mathrm{Ni}$ catalysts. The low calcination temperature at $700^{\circ} \mathrm{C}$ did not produce highly crystalline

\begin{tabular}{|c|c|c|c|c|c|c|c|}
\hline Denotation & Composition & $\begin{array}{l}\text { Theoretical Ni } \\
\text { content [wt \%] }\end{array}$ & \multicolumn{3}{|c|}{ Content (from ICP-MS) [wt \%] } & Calculated formula unit & $\begin{array}{l}\text { SSA } \\
{\left[\mathrm{m}^{2} \mathrm{~g}^{-1}\right]}\end{array}$ \\
\hline LFO & $\mathrm{LaFeO}_{3 \pm \delta}$ & 0.0 & 56.6 & 23.2 & 0.0 & $\mathrm{La}_{0.982} \mathrm{FeO}_{3 \pm \delta}$ & 11.2 \\
\hline LFO-5Ni & $\mathrm{Ni} / \mathrm{LaFeO}_{3 \pm \delta}$ & 1.2 & 58.2 & 23.7 & 1.2 & 1.2 wt $\% \mathrm{Ni} / \mathrm{La}_{0.982} \mathrm{FeO}_{3 \pm \delta}$ & 13.2 \\
\hline LFO-20Ni & $\mathrm{Ni} / \mathrm{LaFeO}_{3 \pm \delta}$ & 4.8 & 58.2 & 23.2 & 4.6 & 4.6 wt $\% \mathrm{Ni} / \mathrm{La}_{0.982} \mathrm{FeO}_{3 \pm \delta}$ & 21.8 \\
\hline LFNO-5Ni & $\mathrm{LaFe}_{0.95} \mathrm{Ni}_{0.05} \mathrm{O}_{3 \pm \delta}$ & 1.2 & 58.1 & 22.4 & 1.2 & $\mathrm{LaFe}_{0.954} \mathrm{Ni}_{0.047} \mathrm{O}_{3 \pm \delta}$ & 13.1 \\
\hline LFNO-10Ni & $\mathrm{LaFe}_{0.9} \mathrm{Ni}_{0.1} \mathrm{O}_{3 \pm \delta}$ & 2.4 & 59.4 & 21.8 & 2.3 & $\mathrm{La}_{0.997} \mathrm{Fe}_{0.909} \mathrm{Ni}_{0.091} \mathrm{O}_{3 \pm \delta}$ & 11.6 \\
\hline LFNO-15Ni & $\mathrm{LaFe}_{0.85} \mathrm{Ni}_{0.15} \mathrm{O}_{3 \pm \delta}$ & 3.6 & 60.4 & 20.8 & 3.4 & $\mathrm{LaFe}_{0.858} \mathrm{Ni}_{0.135} \mathrm{O}_{3 \pm \delta}$ & 9.5 \\
\hline LFNO-20Ni & $\mathrm{LaFe}_{0.8} \mathrm{Ni}_{0.2} \mathrm{O}_{3 \pm \delta}$ & 4.8 & 60.8 & 20.3 & 4.9 & $\mathrm{La}_{0.980} \mathrm{Fe}_{0.814} \mathrm{Ni}_{0.186} \mathrm{O}_{3 \pm \delta}$ & 12.4 \\
\hline LNO & $\mathrm{LaNiO}_{3 \pm \delta}$ & 23.8 & - & - & 23.8 & - & - \\
\hline
\end{tabular}



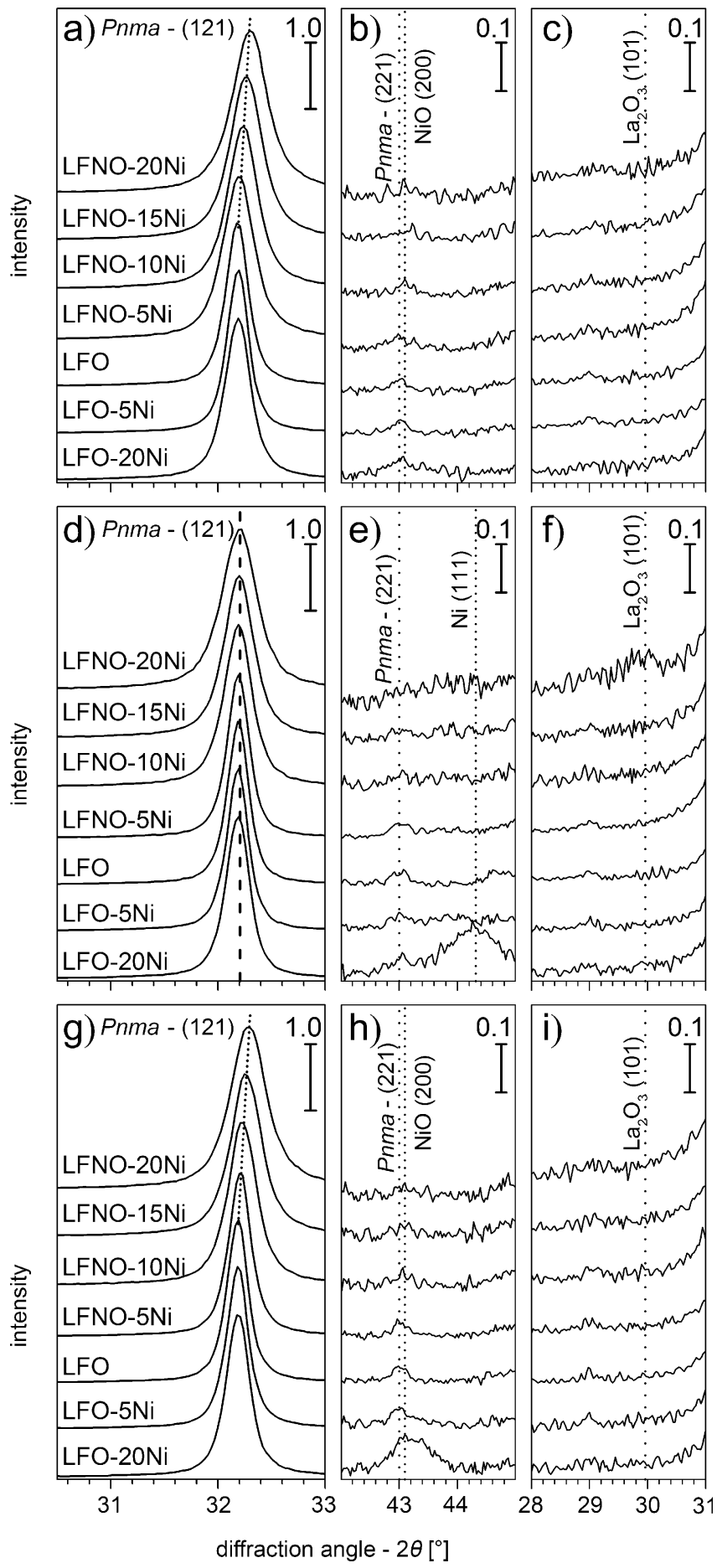

Figure 1. Selected regions of the XRD patterns of $\mathrm{LaFe}_{1-x} \mathrm{Ni}_{x} \mathrm{O}_{3 \pm \delta}(x=0,0.05$, $0.10,0.15,0.20)$ and impregnated samples $\left(1.2 \mathrm{wt} \% \mathrm{Ni}^{\prime} / \mathrm{LaFeO}_{3 \pm \delta}\right.$ and 4.8 wt $\% \mathrm{Ni} / \mathrm{LaFeO}_{3 \pm \delta}$ ) after calcination at a-c) $700{ }^{\circ} \mathrm{C}$, d-f) reduced in $10 \mathrm{vol} \% \mathrm{H}_{2}$ at $600^{\circ} \mathrm{C}$ for $1 \mathrm{~h}$, and g-i) reoxidized in $20 \mathrm{vol} \% \mathrm{O}_{2}$ at $650^{\circ} \mathrm{C}$ for $2 \mathrm{~h}$. The positions of the $\mathrm{LaFeO}_{3}(221)$ reflection at $2 \theta=43.002^{\circ}$, the $\mathrm{NiO}$ (200) reflection at $2 \theta=43.096^{\circ}$, the $\mathrm{Ni}(111)$ reflection at $2 \theta=44.508^{\circ}$, and the $\mathrm{La}_{2} \mathrm{O}_{3}(101)$ reflection at $2 \theta=29.961^{\circ}$ are indicated with dotted lines.

and single-phase materials for high $\mathrm{Ni}$ contents (Figure S2). The rhombohedral perovskite phase of $\mathrm{LaNiO}_{3 \pm \delta}$ was observed for $x>0.5$, and an inspection of the $2 \theta=42.5-44.5^{\circ}$ region (Figure S2 b) revealed the appearance of the $\mathrm{NiO}(200)$ reflec- tion for $x \geq 0.4$ and thus the segregation of $\mathrm{NiO}$. This places the apparent solubility limit of $\mathrm{Ni}$ in this series of $\mathrm{LaFe}_{1-x} \mathrm{Ni}_{x} \mathrm{O}_{3 \pm \delta}$ (LFNO) materials at this value, which is likely a consequence of the low calcination temperature. Furthermore, strong peak broadening with increasing $\mathrm{Ni}$ content was observed for all reflections, which indicates a lower crystallinity and low phase purity for the high-Ni-content samples. Single-phase and highly crystalline materials can also be synthesized for high $\mathrm{Ni}$ contents, but the longer calcination times and/or higher calcination temperatures produce materials with a lower SSA. ${ }^{[39,46]}$ For this reason, the $\mathrm{Ni}$ content of the samples described in the following was limited to $4.8 \mathrm{wt} \%$, which corresponded to a Fe substitution degree of $x \leq 0.2$ in $\mathrm{LaFe}_{1-x} \mathrm{Ni}_{x} \mathrm{O}_{3 \pm \delta}$. A second reason to limit the $\mathrm{Ni}$ content was the necessity to preserve most of the perovskite host lattice during reduction to sustain the reincorporation of $\mathrm{Ni}$ into the perovskite lattice upon the reoxidation of the material (self-regenerating function) at a moderate reoxidation temperature. This will be discussed in further detail below.

\section{X-ray diffraction}

The average crystallite size was calculated on all powder samples using the Scherrer equation ${ }^{[47]}$ by considering the full width at half maximum (FWHM) of the main $\mathrm{LaFe}_{1-x} \mathrm{Ni}_{x} \mathrm{O}_{3 \pm \delta}$ (121) reflection and the $(202)$ reflection at $2 \theta=46.3^{\circ}$ (Table S1). The average crystallite size of the calcined materials decreased with increasing $\mathrm{Ni}$ content from $30 \mathrm{~nm}$ in LFO to below $20 \mathrm{~nm}$ in LFNO-20Ni. Peak broadening with increasing $\mathrm{Ni}$ content in $\mathrm{LaFe}_{1-x} \mathrm{Ni}_{x} \mathrm{O}_{3 \pm \delta}$, and hence lower crystallite size values, is generally observed for this material. ${ }^{[43,48]}$ The actual grain size of LFNO-type materials may be slightly larger because lower degrees of crystallinity can lead to an underestimation of the actual crystallite size as derived from the Scherrer equation. The impregnation of LFO with nickel nitrate appears to reduce the perovskite crystallite size, possibly because of the partial dissolution or leaching of $\mathrm{LaFeO}_{3}$ by nitric acid produced from the Ni precursor solution. Likewise, similar phenomena have been observed and reported for the impregnation of plain metal oxides with nickel nitrate precursor solution or direct treatment with dilute nitric acid. ${ }^{[49-51]}$

After reduction at $600^{\circ} \mathrm{C}$ for $1 \mathrm{~h}$, the XRD data showed a shift of the main reflection for all LFNO materials towards the $2 \theta$ value of $\mathrm{Ni}$-free $\mathrm{LaFeO}_{3}$ (Figure $1 \mathrm{~d}$ ). This is interpreted as the exsolution of $\mathrm{Ni}$ from the perovskite lattice and, consequently, an increased shift with increasing $\mathrm{Ni}$ content. The (111) reflection of metallic Ni clearly appeared in the diffractogram of the impregnated sample, LFO-20Ni, whereas it was very weak in that of LFNO-20Ni. This reflection was not visible in any other sample likely because of the low number, low crystallinity, or small size of the Ni particles obtained upon reduction. Furthermore, the $\mathrm{La}_{2} \mathrm{O}_{3}(101)$ reflection appeared in the pattern of reduced LFNO-20Ni. The presence of both reflections confirmed the reduction of $\mathrm{Ni}^{n+}{ }_{\text {oct }}$. As a result of the generally low noble metal content considered in previous studies on the segregation behavior, it has been debated whether the perovskite lattice is capable of stabilizing B-site 
vacancies, which remain unoccupied until the material is reoxidized and the segregated B-site element reincorporated. ${ }^{[6]}$ In the case of LFNO-type materials, the observed formation of $\mathrm{La}_{2} \mathrm{O}_{3}$ encourages us to conclude that $\mathrm{Ni}^{\mathrm{n+}}$ oct-containing unit cells collapse upon reduction and that $\mathrm{Ni}$ reincorporation is achieved through the solid-state reaction of $\mathrm{La}_{2} \mathrm{O}_{3}$ and $\mathrm{NiO}$. Lower reoxidation temperatures are sufficient for perovskite lattice formation from the single oxides because their crystallites are sufficiently small. ${ }^{[52]}$

The reflections observed initially in the calcined materials were restored after reoxidation at $650^{\circ} \mathrm{C}$ for $2 \mathrm{~h}$ (Figure $1 \mathrm{~g}$-i). Impregnated samples exhibited narrower reflections of $\mathrm{NiO}$ after reoxidation, which is indicative of $\mathrm{NiO}$ crystallite growth

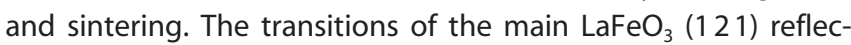
tion over the course of the full redox cycle are further visualized in Figure S3. The position of this reflection did not change in the patterns of the impregnated samples and LFO, which suggests that $\mathrm{LaFeO}_{3}$ was not involved in the redox cycle. However, the reflection shifted significantly during the reduction and reoxidation of LFNO-type materials, and the effect intensified with increasing $\mathrm{Ni}$ content. These observations support a preferential reduction of the Ni present within the LFNO lattice $\left(\mathrm{Ni}^{\mathrm{n+}}{ }_{\text {oct }}\right)$ and of the exsolution of $\mathrm{Ni}^{0}$ to the crystallite surface, which appeared to be enhanced for samples with a higher Ni content. The similar lattice parameters of reduced LFNO and LFO also suggest that the nominal transition of LFNO to a mixture of LFO and $\mathrm{Ni}^{0} / \mathrm{La}_{2} \mathrm{O}_{3}$ occurred during reduction, followed by the restoration of LFNO upon reoxidation.

The diffractograms of LFO and LFNO-type materials in their reduced state after five redox cycles are identical to those obtained after a single reduction treatment, except that the $\mathrm{La}_{2} \mathrm{O}_{3}$ (101) reflection was no longer visible (Figure S4). The Ni (111) reflection appeared in the XRD pattern of the high-Ni-content sample, LFNO-20Ni, and on both impregnated samples. Over the course of the redox cycles, this reflection narrowed significantly in the case of the impregnated samples. Taking into account that peak narrowing in XRD is primarily caused by crystallite growth, these observations indicate $\mathrm{Ni}$ sintering on the impregnated materials as a result of the consecutive redox cycles. However, LFNO-type materials are more resistant against this catalyst degeneration process despite the slight increase of the host perovskite crystallite size over the number of redox cycles. This can be because of incomplete structural stabilization after the relatively short calcination times at the end of the synthesis.

\section{Temperature-programmed reduction}

The reducibility of all calcined LFNO materials was explored by considering the $\mathrm{H}_{2}$ consumption during temperature programmed reduction (TPR). $\mathrm{LaFeO}_{3 \pm \delta}$ showed a very low $\mathrm{H}_{2}$ consumption up to $720^{\circ} \mathrm{C}$ while $\mathrm{LaNiO}_{3 \pm \delta}$ was reduced completely at $600^{\circ} \mathrm{C}$ (Figure S5). For Ni-containing samples three reduction events over three different temperature ranges can be identified, the extent of which depends strongly on sample composition. As all LFNO-type materials are solid solutions of $\mathrm{LaFeO}_{3 \pm \delta}$ and $\mathrm{LaNiO}_{3 \pm \delta}$, of which only $\mathrm{LaNiO}_{3 \pm \delta}$ appears to contribute to the reduction, it is reasonable to compare these reduction events to that of $\mathrm{LaNiO}_{3 \pm \delta}$, which has been reported to reduce by a two-step pathway and via a $\mathrm{La}_{2} \mathrm{Ni}_{2} \mathrm{O}_{5}$ intermediate. ${ }^{[53]}$ This pathway also includes the formation of $\mathrm{Ni}^{0}$ and $\mathrm{La}_{2} \mathrm{O}_{3}$ as intermediate products. Alternatively, a three-step reduction pathway via a Ruddlesden-Popper-type phase ${ }^{[54]}$ and $\mathrm{La}_{2} \mathrm{NiO}_{4}$ as well as $\mathrm{NiO}$ intermediates was also proposed. ${ }^{[55,56]}$ The presence of $\mathrm{La}_{2} \mathrm{O}_{3}$ observed using XRD after the reduction of LFNO-20Ni (Figure $1 \mathrm{c}$ ) at $600^{\circ} \mathrm{C}$ indicates that the reduction in LFNO follows the two-step pathway.

In either case, in our materials the first reduction event below $300^{\circ} \mathrm{C}$ corresponds to the reduction of what we have defined above as $\mathrm{Ni}^{n+}{ }_{\text {oct }}^{[17,39,40]}$ and is present for all LFNO compositions. Its extent increased with the overall $\mathrm{Ni}$ content, which thus demonstrates the direct correlation between $\mathrm{Ni}$ content and overall perovskite reducibility. Careful inspection of the shape of this first peak revealed a low-temperature shoulder that can be attributed to the partial reduction of $\mathrm{Ni}^{n+}$ oct to $\mathrm{Ni}^{2+}$ whereas the main signal was assigned to the reduction of $\mathrm{Ni}^{2+}$ to metallic $\mathrm{Ni}^{0}$. An intermediate-temperature reduction event occurred for $x \geq 0.4$ at $310-430^{\circ} \mathrm{C}$. This event has been previously assigned to the reduction of a fraction of $\mathrm{Fe}^{3+}$ to $\mathrm{Fe}^{2+}$ in the bulk of LFNO. ${ }^{[17]}$ However, we found that it correlated with the reduction of $\mathrm{Ni}^{2+}$ species present outside the perovskite lattice, which are present because of the incomplete $\mathrm{Ni}$ incorporation into the $\mathrm{B}$-site during the low-temperature calcination at $700^{\circ} \mathrm{C}$. This is in agreement with the presence of $\mathrm{NiO}$ in high-Ni-content LFNO samples from the XRD data (Figure S2), and a similar reduction feature is present for impregnated NiO/LFO (Figure $2 \mathrm{f}$ ).

Finally, a high-temperature reduction was observed for all compositions. The maximum $\mathrm{H}_{2}$ consumption of the high-temperature event shifted with increasing $\mathrm{Ni}$ content from above $800^{\circ} \mathrm{C}$ for LFO to $475^{\circ} \mathrm{C}$ for $\mathrm{LaNiO}_{3 \pm \delta}$ (Figure S5). In agreement with previous reports, this high-temperature event was attributed to the structural changes that occurred during reduction as a result of the collapse of the perovskite lattice into metallic B-site elements and $\mathrm{La}_{2} \mathrm{O}_{3} \cdot{ }^{[53,55,57]}$

Based on the above interpretation of the reduction thermograms, TPR can be used to distinguish between different coordination and oxidation states of $\mathrm{Ni}$ in LFNO samples, that is, surface $\mathrm{Ni}^{2+}$ species, organized into $\mathrm{NiO}$ entities of variable size, and $\mathrm{Ni}^{n+}{ }_{\text {oct }}$ species. The reduction of $\mathrm{Ni}^{2+}$ and $\mathrm{Ni}^{n+}$ oct occurred in well-separated temperature regions, and the reduction of $\mathrm{Ni}^{n+}$ oct occurred at a lower temperature. As Fe reducibility was very limited in these materials (indicated by the flat TPR profile of LFO), we used TPR reduction-reoxidation cycles to estimate the reoxidation temperature at which $\mathrm{Ni}$ can be reversibly incorporated into the perovskite lattice $\left(\mathrm{Ni}^{n+}{ }_{\text {oct }}\right)$ instead of remaining at the surface of the perovskite as $\mathrm{NiO}$ after reoxidation $\left(\mathrm{Ni}^{2+}\right)$. The experimental procedure of this redox series is summarized in Figure S6. The results obtained for LFO, LFNO-5Ni, LFNO-10Ni, LFNO-15Ni, LFNO-20Ni, and LFO-20Ni are presented in Figure 2. Calcined LFO exhibited only a weak and broad reduction feature between 350 and $550{ }^{\circ} \mathrm{C}$ in agreement with its poor reducibility, whereas all of the LFNO-type materials showed the distinct $\mathrm{Ni}^{n+}$ oct $\rightarrow \mathrm{Ni}^{2+} \rightarrow \mathrm{Ni}^{0}$ reduction at 

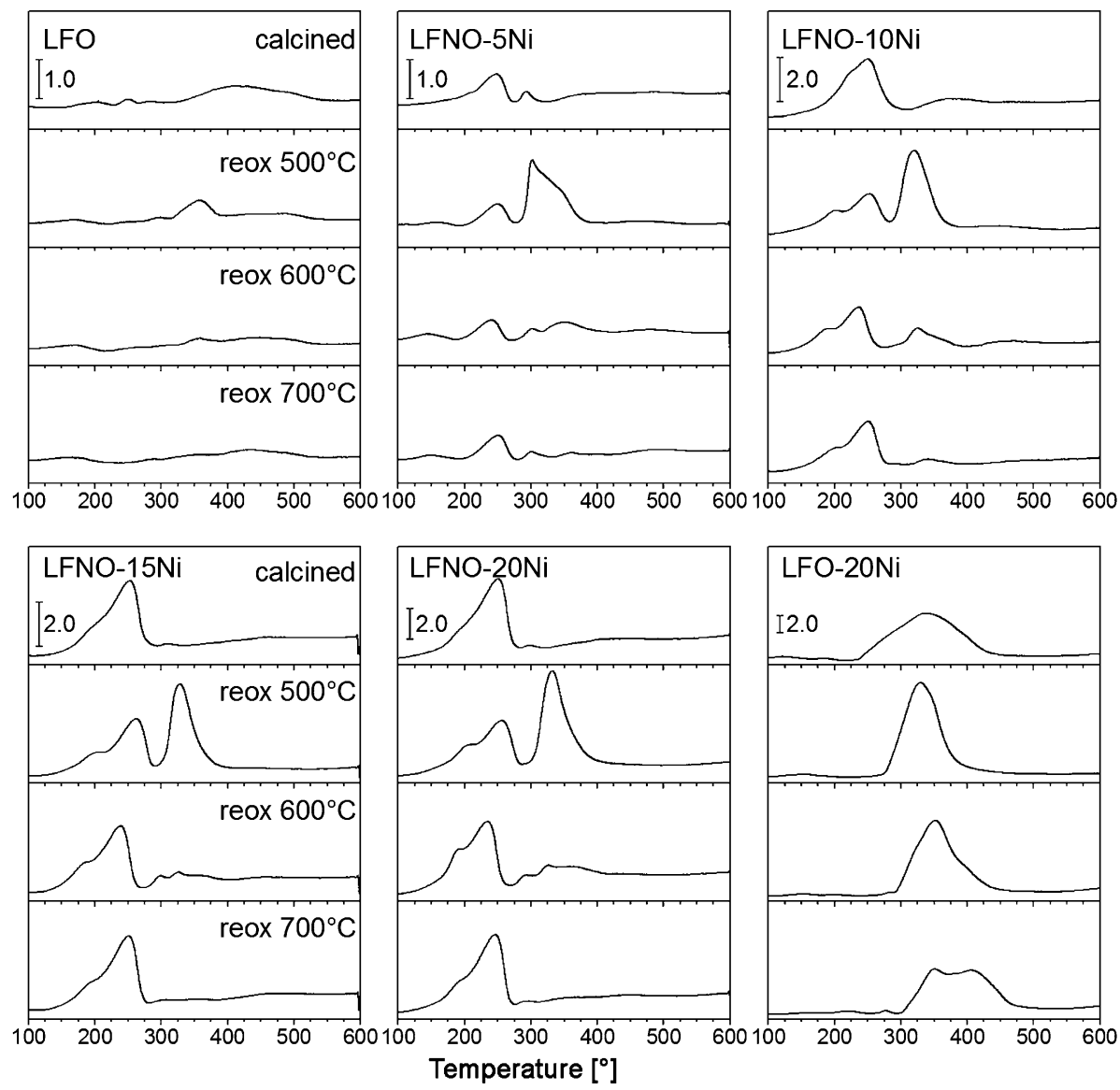

Figure 2. Temperature-programmed reduction-reoxidation cycles for LFO, LFNO-5Ni, LFNO-10Ni, LFNO-15Ni, LFNO-20Ni, and LFO-20Ni (top left to bottom right). Hydrogen consumption values were normalized by the mass of the samples. Reoxidized samples were prereduced in 10 vol\% $\mathrm{H}_{2}$ at $600{ }^{\circ} \mathrm{C}$ for $1 \mathrm{~h}$ before reoxidation at the given temperature $\left(20 \mathrm{vol} \% \mathrm{O}_{2}, 2 \mathrm{~h}\right)$.

$240^{\circ} \mathrm{C}$ as discussed above. The TPR of impregnated LFO-20Ni (Figure $2 \mathrm{f}$ ) was markedly different and displayed the feature expected for the reduction of $\mathrm{NiO}$ with a maximum $\mathrm{H}_{2}$ consumption at $340^{\circ} \mathrm{C}$. The broad reduction feature of LFO (Figure $2 \mathrm{a}$ ) changed into a small but distinct peak centered at $360^{\circ} \mathrm{C}$ after reoxidation at $500^{\circ} \mathrm{C}$. Peak area integration revealed the reduction of $0.3 \mathrm{~mol} \% \mathrm{Fe}^{3+}$ (if we assume the reduction of $\mathrm{Fe}^{3+}$ to $\mathrm{Fe}^{2+}$ ). The slight excess of Fe compared to La (Table 1) could have been responsible for the formation of iron oxide species that appear in the thermograms after recrystallization during redox cycling. The distinctive $\mathrm{NiO}$ reduction feature at around $350^{\circ} \mathrm{C}$ appeared in the TPR profile of LFNOtype materials after the first reoxidation at $500^{\circ} \mathrm{C}$, which suggests that the reoxidation temperature was not sufficient to restore $\mathrm{Ni}^{n+}$ oct species to the initial levels. Increasing the reoxidation temperature caused the intensity of this feature to decrease until it disappeared completely after reoxidation at $700{ }^{\circ} \mathrm{C}$ and only the reduction feature of $\mathrm{Ni}^{n+}{ }_{\text {oct }}$ remained. The thermograms of LFNO samples are then identical to those of the initial samples. These observations are interpreted as the reincorporation of an increasing amount of $\mathrm{Ni}$ inside the $\mathrm{LaFeO}_{3}$ lattice with increasing reoxidation temperature whereas a decreasing fraction of $\mathrm{NiO}$ remained on the surface. All LFNO samples still showed a weak NiO contribution after reoxi- dation at $600^{\circ} \mathrm{C}$, which disappeared completely after reoxidation at $700^{\circ} \mathrm{C}$. Therefore, complete Ni reincorporation into the perovskite host lattice was achieved in the temperature range of $600-700^{\circ} \mathrm{C}$ for all samples. This indicates that the reincorporation temperature is not strongly affected by the $\mathrm{Ni}$ content for $x \leq 0.2$. A comparison with the higher temperatures reported for $\mathrm{Ni}$ incorporation into La-doped strontium titanates (another class of PMOs in which $\mathrm{Ni}$ exhibits reversible segregation), suggests that the reincorporation temperature is influenced rather by the nature of the other A- and B-site cations in the structure. ${ }^{[37]}$ This behavior is essentially identical to that of precious-metal-substituted $\mathrm{LaFeO}_{3}$.

In contrast to the LFNO materials, LFO-20Ni showed a strong feature of $\mathrm{NiO}$ reduction after all reoxidation steps and no reduction events were present below $300^{\circ} \mathrm{C}$. Therefore, we can assume that at the temperatures investigated in this work, impregnated $\mathrm{Ni}^{2+}$ cannot enter a B-site stoichiometric $\mathrm{LaFeO}_{3 \pm \delta}$ lattice if no free La (e.g., in the form of $\mathrm{La}_{2} \mathrm{O}_{3}$ ) is available to form the perovskite lattice and all $\mathrm{B}$-sites remain occupied by $\mathrm{Fe}$. The fact that no exchange between the B-site cation $\left(\mathrm{Fe}^{3+}\right)$ and surface $\mathrm{Ni}^{2+}$ occurs can be explained by the lower enthalpy of formation and hence the greater stability of $\mathrm{LaFeO}_{3 \pm \delta}$ $\left(\Delta H_{\mathrm{f}, \text { oxides }}^{0}=-64 \mathrm{~kJ} \mathrm{~mol}^{-1}\right)$ compared to $\mathrm{LaNiO}_{3 \pm \delta}\left(\Delta H_{\mathrm{f}, \text { oxides }}^{0}=\right.$ $\left.-57 \mathrm{~kJ} \mathrm{~mol}^{-1}\right) .^{[58]}$ In contrast to reincorporation, the single $\mathrm{NiO}$ 
reduction peak became more defined and narrower after reoxidation at $500^{\circ} \mathrm{C}$, likely as a result of $\mathrm{NiO}$ sintering upon reduction-reoxidation. Reoxidation above $600^{\circ} \mathrm{C}$ produced a new reduction feature in the thermograms but did not affect the overall $\mathrm{H}_{2}$ consumption, which suggests that the amount of available $\mathrm{Ni}^{2+}$ remained constant as expected for well-defined $\mathrm{NiO}$ particles. Changes in $\mathrm{NiO}$ morphology induced by hightemperature treatments are likely the cause of this phenomenon. ${ }^{[59]}$

\section{X-ray absorption spectroscopy}

Direct information on the oxidation and coordination state of $\mathrm{Ni}$ in the various LFNO and impregnated LFO samples was obtained by using X-ray absorption spectroscopy (XAS). The Ni Kedge XANES spectrum of calcined LFNO-20Ni exhibited clear differences in comparison to the spectra of LFO-20Ni and $\mathrm{Ni}$ foil (Figure 3), and the $\mathrm{Ni}$ absorption edge energy $\left(E_{0}\right)$ shifted towards higher values $\left(E_{0}=8.348 \mathrm{keV}\right.$ for LFNO-20Ni, $8.340 \mathrm{keV}$ for LFO-20Ni, and $8.333 \mathrm{keV}$ for $\mathrm{Ni}^{0}$ ). This was confirmed by the analysis of the first derivative. Additionally, clear differences in the shape of the extended whiteline are visible between the spectra of LFNO-20Ni and LFO-20Ni. Although the difference to the $\mathrm{Ni}$ foil is clear, the difference between the spectra of LFNO-20Ni and LFO-20Ni reflects the presence of different $\mathrm{Ni}$ species in the two materials obtained by the two synthesis strategies. The latter is very similar to the spectrum of $\mathrm{NiO}$ and showed a local minimum at $8.360 \mathrm{keV}^{[60]}$ whereas the spectrum of LFNO-20Ni displayed a broad shoulder after the whiteline

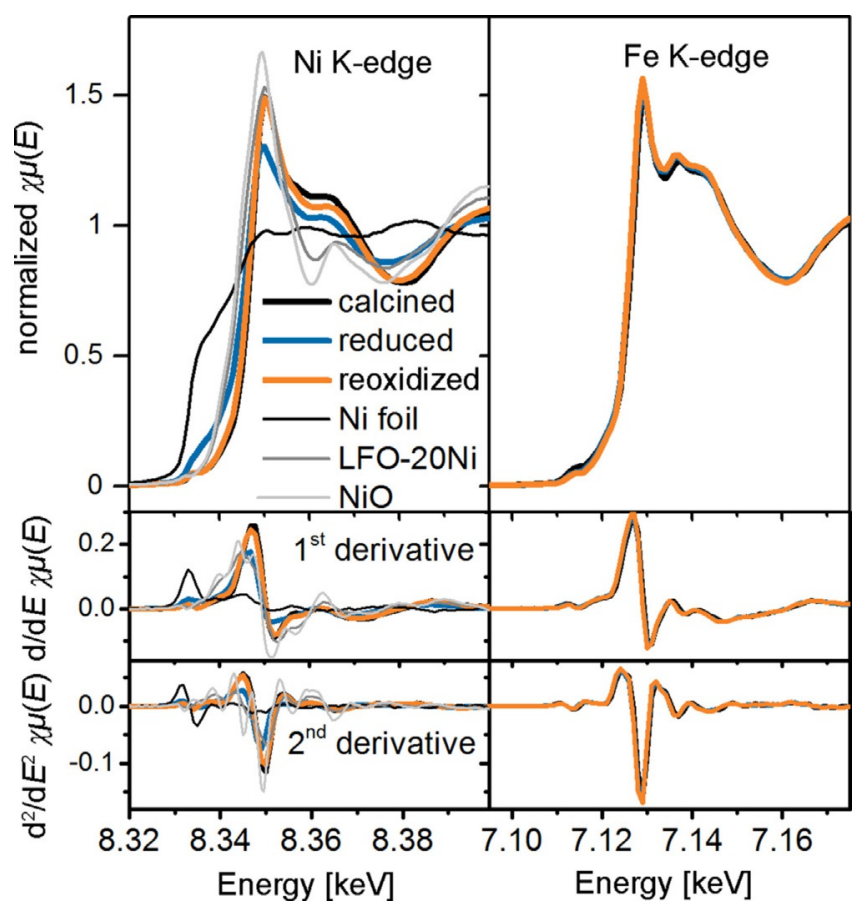

Figure 3. Normalized XANES data and first and second derivatives obtained for LFNO-20Ni around the $\mathrm{Ni}(8.333 \mathrm{keV})$ and Fe K-edges (7.112 keV). Spectra were obtained for calcined, reduced $\left(10 \mathrm{vol} \% \mathrm{H}_{2}, 600^{\circ} \mathrm{C}, 1 \mathrm{~h}\right)$, and reoxidized materials ( $20 \mathrm{vol} \% \mathrm{O}_{2}, 650^{\circ} \mathrm{C}, 1 \mathrm{~h}$ ). The spectra of $\mathrm{Ni}$ foil, $\mathrm{NiO}$, and LFO-20Ni are also shown. maximum. This is also visible in the plots of the first and second derivatives. These substantial differences allowed us to conclude that the spectrum of LFNO-20Ni characterizes different $\mathrm{Ni}$ species than those observed for LFO-20Ni and its XAS spectrum carries the fingerprint of $\mathrm{Ni}^{n+}{ }_{\text {oct }}$, that is, $\mathrm{Ni}$ in the coordination environment of octahedral Fe and at a higher oxidation state than $2+$ within the perovskite lattice. Our assignment is also confirmed by comparison with the spectrum of $\mathrm{LaNiO}_{3}$ calcined at $900^{\circ} \mathrm{C}$ (Figure S9) in which Ni adopts the octahedral coordination of a perovskite B-site. Moreover, the spectrum of LFNO-20Ni resembles that reported for La$\mathrm{Co}_{1-x} \mathrm{Ni}_{x} \mathrm{O}_{3}$ in which $\mathrm{Ni}$ was assigned to $\mathrm{Ni}^{3+},{ }^{[61]}$ and the similarities to $\mathrm{Fe}$ in LFNO-20Ni in the pseudoradial distribution obtained from the $\mathrm{Ni}$ and Fe K-edge extended X-ray absorption fine structure (EXAFS) analysis (vide infra) further support this conclusion. After reduction at $600^{\circ} \mathrm{C}$, the formation of $\mathrm{Ni}^{\circ}$ was confirmed by the shift of the edge position of LFNO-20Ni towards a lower energy and by the significant decrease in the whiteline intensity. Reoxidation at $650^{\circ} \mathrm{C}$ for $1 \mathrm{~h}$ restored the initial spectrum to a large extent instead of changing it to that obtained for LFO-20Ni, which would indicate formation of $\mathrm{Ni}^{2+}$ surface species and incomplete reincorporation. This observation validates our interpretation of the XRD data presented in Figure 1 in which the shift of the (121) reflection during the redox cycle is attributed to the reduction and reincorporation of $\mathrm{Ni}$ into the LFNO lattice. The changes in the XANES spectrum of the impregnated sample LFO-20Ni during the same redox treatment are shown in Figure S7. Redox reversibility in the $\mathrm{Ni}$ species is also present in this sample. However, if we start from a spectrum that suggests the presence of $\mathrm{Ni}^{2+}$, the fact that the spectrum is reversible indicates that $\mathrm{Ni}$ is not incorporated into the LFO perovskite-type lattice over the redox cycle and always remains at the surface as either $\mathrm{NiO}$ or $\mathrm{Ni}^{0}$.

The Fe K-edge XANES spectrum of LFNO-20Ni shown in Figure 3 reflects the coordination of $\mathrm{Fe}$ in the perovskite-type structure $\mathrm{e}^{[62]}$ and shows that Fe was not influenced by reduction and remained in its initial oxidized state throughout the redox cycle. This redox stability is again also visible in the first and second derivatives. However, it has to be taken into account that XAS is a bulk method and that Fe is four times more abundant in this sample than $\mathrm{Ni}$. Thus, changes in the oxidation state and coordination environment of a small fraction of Fe during redox cycling are not easily monitored by using XANES.

The Ni K-edge EXAFS data obtained during the same in situ redox experiments on the LFNO-type materials and LFO-20Ni are presented in Figures 4 and S8. All reference spectra have been fitted to validate the origin of the individual features both in the pseudoradial distribution function and $X(k)$. The fitting results are summarized in Table S2. Reversible Ni segregation was also observed in the $k^{3}$-weighted $X(k)$ functions (Figure 4). First, the structural difference related to the coordination of $\mathrm{Ni}$ in LFNO-20Ni and LFO-20Ni is clearly visible as in the XANES region, and the spectrum of LFO-20Ni (Figure $4 \mathrm{~g}$ ) resembles that of $\mathrm{NiO}$ closely (Figure $4 \mathrm{a}$ ). The spectra of $\mathrm{LaNiO}_{3 \pm \delta}$ and LFNO-20Ni exhibited a clear double feature between 5.2 and $7.1 \AA^{-1}$, which was not present in the spectra of 

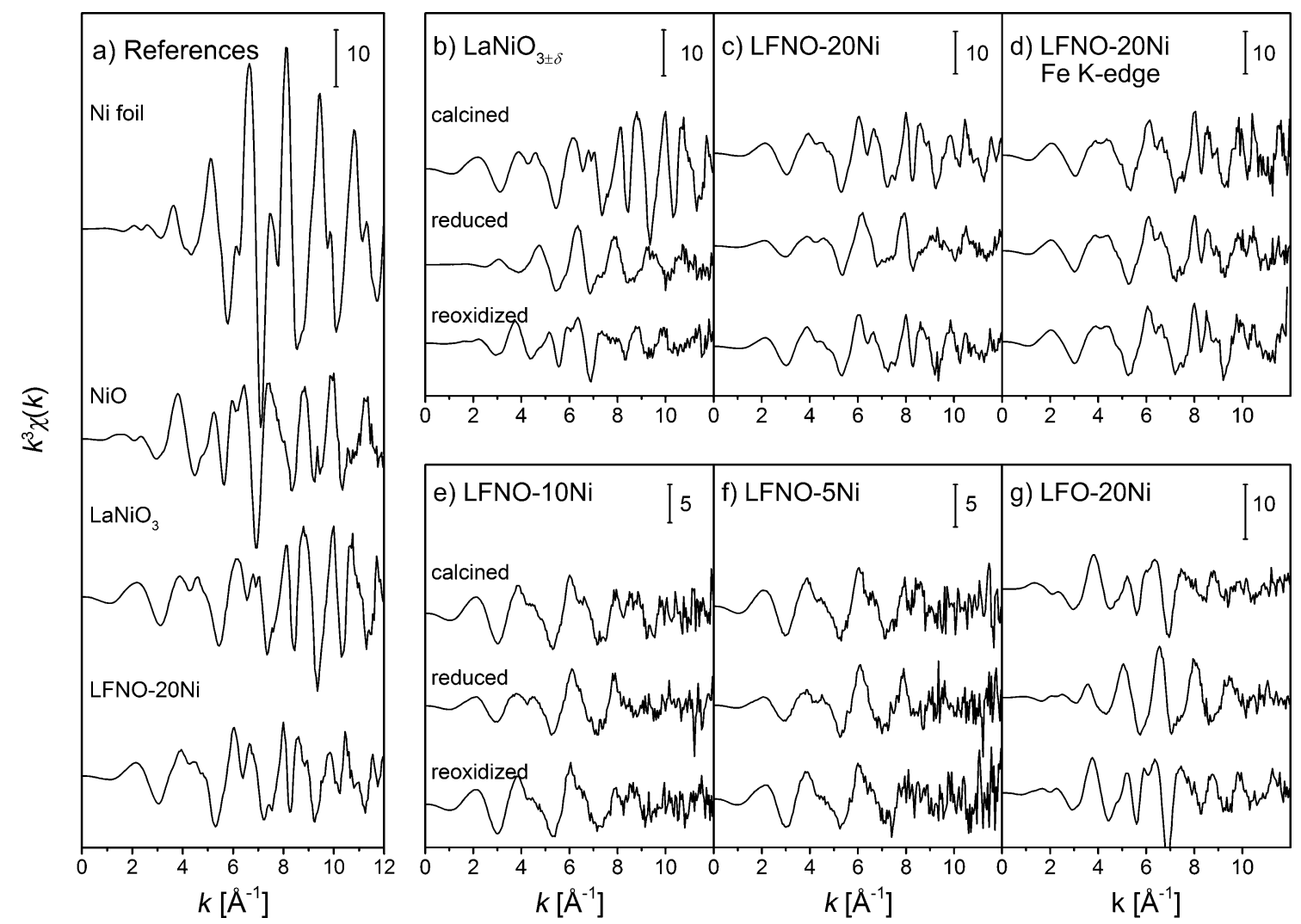

Figure 4. EXAFS plots of $k^{3}$-weighted $X(k)$ of calcined materials after reduction $\left(10\right.$ vol $\left.\% \mathrm{H}_{2}, 600{ }^{\circ} \mathrm{C}, 1 \mathrm{~h}\right)$ and reoxidation $\left(20\right.$ vol $\left.\% \mathrm{O}_{2}, 650{ }^{\circ} \mathrm{C}, 2 \mathrm{~h}\right)$. a) Reference compounds, b) $\mathrm{LaNiO}_{3 \pm \delta}$, c) LFNO-20Ni, and d) LFNO-20Ni. Fe K-edge data of e) LFNO-10Ni, f) LFNO-5Ni, and g) LFO-20Ni.

the metallic $\mathrm{Ni}$ or $\mathrm{NiO}$ references and which reinforces their structural similarity. At these $k$ values the spectral shape in perovskite-type samples is dominated by the heavy-scattering-element La and to some extent by the Fe/Ni neighbors. This is why the above described double feature was observed in all calcined materials except LFO-20Ni and can be used as a spectral fingerprint of $\mathrm{Ni}^{\text {n+ }}$ oct in $k$ space. The Fe K-edge data of LFNO-20Ni displayed in Figure $4 \mathrm{~d}$ shows the exact same feature, confirming that $\mathrm{Ni}$ occupies the same lattice sites and has the same coordination environment as $\mathrm{Fe}$ inside $\mathrm{LaFeO}_{3}$. Reduction caused the intensity of the second peak in this double feature to decrease for $\mathrm{Ni}$ inside a PMO (Figure $4 \mathrm{~b}, \mathrm{c}$, e, f); however, the Fe K-edge spectrum (Figure $4 \mathrm{~d}$ ) was not affected. This is in agreement with the stability of $\mathrm{LaFeO}_{3 \pm \delta}$ against reduction under these conditions. Reoxidation at $650^{\circ} \mathrm{C}$ largely restored the original spectrum of all LFNO samples (Figure $4 c$, e, and f), which demonstrates that $\mathrm{Ni}$ is capable of adopting the same initial coordination environment within the perovskite lattice. $\mathrm{LaNiO}_{3 \pm \delta}$ (Figure $4 \mathrm{~b}$ ) demonstrated an exception to this structural reversibility at $650{ }^{\circ} \mathrm{C}$. After the reduction of $\mathrm{LaNiO}_{3 \pm \delta}$ to $\mathrm{Ni}^{0} / \mathrm{La}_{2} \mathrm{O}_{3}$, as suggested by the EXAFS data, reoxidation did not restore the original double feature of $\mathrm{Ni}^{n+}{ }_{\text {oct }}$ instead the spectrum resembled that of $\mathrm{NiO}$. The complete collapse of the perovskite-type structure during the reduction of $\mathrm{LaNiO}_{3 \pm \delta}$ entails a loss of structural reversibility that can be ensured only by reoxidation at higher temperatures. Finally, the reversibility of the spectra obtained for LFO-20Ni over the redox cycle (Figure $4 \mathrm{~g}$ ) confirmed that $\mathrm{Ni}$ is not incorporated into the stoichiometric LFO support at these temperatures.

The pseudoradial distribution function of metallic Ni (Figure 58 a) showed a single strong signal at $2.16 \AA$. This peak corresponds to the first $\mathrm{Ni}$ coordination shell (Table $\mathrm{S} 2$ ). NiO showed peaks at $1.64 \AA$ corresponding to the first oxygen coordination shell (Ni-O), and at $2.57 \AA$, which can be assigned to the first $\mathrm{Ni}$ coordination shell (Ni-O-Ni). The first oxygen shell of $\mathrm{LaNiO}_{3 \pm \delta}(1.47 \AA)$ and LFNO-20Ni (1.52 $\AA$ ) appeared at lower distances than that of $\mathrm{NiO}$. The shorter $\mathrm{Ni}-\mathrm{O}$ bond distance is explained by the higher charge on $\mathrm{Ni}^{n+}$ oct than on $\mathrm{Ni}^{2+}$. The second intense feature in the pseudoradial distribution function of $\mathrm{LaNiO}_{3 \pm \delta}$ at $3.15 \AA$ and LFNO-20Ni at $3.21 \AA$ corresponds to the first La coordination shell. ${ }^{[63]}$ The small feature at $1.63 \AA$ observed for $\mathrm{LaNiO}_{3 \pm \delta}$ was likely caused by $\mathrm{Ni}-\mathrm{O}$ bonds because of the presence of small amounts of $\mathrm{NiO}$ in the reference sample as observed by using XRD (Figure S2). Nevertheless, the differences in coordination shell radii allowed us to observe $\mathrm{Ni}$ reincorporation in situ. $\mathrm{LaNiO}_{3 \pm \delta}$ was reduced completely to $\mathrm{Ni}^{0}$ at $600^{\circ} \mathrm{C}$. However, most $\mathrm{Ni}$ was only oxidized to $\mathrm{NiO}$ after reoxidation as indicated by the features at 1.47 and $2.49 \AA$ (Figure S8 b). A similar behavior was observed for LFO$20 \mathrm{Ni}$ (Figure $\mathrm{S} 8 \mathrm{~g}$ ), in which $\mathrm{NiO}$ was completely reduced to $\mathrm{Ni}^{0}$ and completely reoxidized to $\mathrm{NiO}$. This is in full agreement with the $\mathrm{H}_{2}$-TPR data shown in Figure 2. The pseudoradial distribution functions of the LFNO-type samples (Figure S8c, e, and f) again confirm and demonstrate the intrinsic structural 


\begin{tabular}{|c|c|c|c|c|c|c|}
\hline Sample & Pretreatment & \multicolumn{3}{|c|}{ Species content1 [\%] } & $R_{\mathrm{fit}}$ & $X_{\text {red }}^{2}$ \\
\hline \multirow{4}{*}{ LFO-20Ni } & calcined & 0 & 100 & 0 & 0.02 & 0.004 \\
\hline & 10 vol $\% \mathrm{H}_{2} / 600^{\circ} \mathrm{C} / 1 \mathrm{~h}$ & 0 & $15 \pm 3$ & $85 \pm 3$ & 0.01 & 0.002 \\
\hline & $20 \mathrm{vol} \% \mathrm{O}_{2} / 650^{\circ} \mathrm{C} / 1 \mathrm{~h}$ & 0 & $100 \pm 0$ & 0 & 0.001 & 0.0003 \\
\hline & $20 \mathrm{vol} \% \mathrm{O}_{2} / 650^{\circ} \mathrm{C} / 1 \mathrm{~h}$ & 0 & $100 \pm 0$ & 0 & 0.009 & 0.002 \\
\hline \multirow{4}{*}{ LFNO-5Ni } & calcined & 100 & 0 & 0 & - & - \\
\hline & $10 \mathrm{vol} \% \mathrm{H}_{2} / 600^{\circ} \mathrm{C} / 1 \mathrm{~h}$ & $65 \pm 4$ & 0 & $35 \pm 3$ & 0.008 & 0.001 \\
\hline & $20 \mathrm{vol} \% \mathrm{O}_{2} / 650^{\circ} \mathrm{C} / 1 \mathrm{~h}$ & $83 \pm 3$ & $17 \pm 1$ & 0 & 0.0002 & 0.00004 \\
\hline & $20 \mathrm{vol} \% \mathrm{O}_{2} / 650^{\circ} \mathrm{C} / 1 \mathrm{~h}$ & - & - & - & - & - \\
\hline \multirow{4}{*}{ LFNO-10Ni } & calcined & 100 & 0 & 0 & - & - \\
\hline & $10 \mathrm{vol} \% \mathrm{H}_{2} / 600^{\circ} \mathrm{C} / 1 \mathrm{~h}$ & $60 \pm 3$ & 0 & $40 \pm 3$ & 0.009 & 0.001 \\
\hline & $20 \mathrm{vol} \% \mathrm{O}_{2} / 650^{\circ} \mathrm{C} / 1 \mathrm{~h}$ & $88 \pm 1$ & $12 \pm 1$ & 0 & 0.0001 & 0.00002 \\
\hline & $20 \mathrm{vol} \% \mathrm{O}_{2} / 650^{\circ} \mathrm{C} / 1 \mathrm{~h}$ & - & - & - & - & - \\
\hline \multirow{4}{*}{ LFNO-20Ni } & calcined & 100 & 0 & 0 & - & - \\
\hline & 10 vol $\% \mathrm{H}_{2} / 600^{\circ} \mathrm{C} / 1 \mathrm{~h}$ & $51 \pm 3$ & 0 & $49 \pm 3$ & 0.009 & 0.001 \\
\hline & $20 \mathrm{vol} \% \mathrm{O}_{2} / 650^{\circ} \mathrm{C} / 1 \mathrm{~h}$ & $84 \pm 1$ & $16 \pm 1$ & 0 & 0.00005 & 0.00001 \\
\hline & $20 \mathrm{vol} \% \mathrm{O}_{2} / 650^{\circ} \mathrm{C} / 1 \mathrm{~h}$ & $100 \pm 2$ & $0 \pm 2$ & 0 & 0.002 & 0.0004 \\
\hline \multirow{4}{*}{$\mathrm{LaNiO}_{3 \pm \delta}$} & calcined & 100 & 0 & 0 & - & - \\
\hline & 10 vol $\% \mathrm{H}_{2} / 600^{\circ} \mathrm{C} / 1 \mathrm{~h}$ & 0 & 0 & 100 & 0.003 & 0.0004 \\
\hline & $20 \mathrm{vol} \% \mathrm{O}_{2} / 650^{\circ} \mathrm{C} / 1 \mathrm{~h}$ & $34 \pm 8$ & $66 \pm 8$ & 0 & 0.03 & 0.008 \\
\hline & $20 \mathrm{vol} \% \mathrm{O}_{2} / 650^{\circ} \mathrm{C} / 1 \mathrm{~h}$ & $32 \pm 3$ & $68 \pm 3$ & 0 & 0.006 & 0.001 \\
\hline
\end{tabular}

reversibility of these materials. $\mathrm{Ni}^{n+}{ }_{\text {oct }}$ was partially reduced and segregated out of the perovskite lattice, forming $\mathrm{Ni}-\mathrm{Ni}$ bonds indicative of metallic Ni particles. This is visible from the development of the signal at $2.1 \AA$ during reduction. After reoxidation most Ni re-entered the perovskite lattice. The pseudoradial distribution function obtained for Fe in LFNO-20Ni (Figure $\mathrm{S} 8 \mathrm{~d}$ ) over this redox cycle changed only marginally, which again confirms the stability of $\mathrm{Fe}^{3+}$ in the perovskite lattice.

The magnitude of $E_{0}$ and the linear combination fitting of the XANES region delivered a quantitative estimate of the amount of reducible $\mathrm{Ni}$ in LFNO, which depends on the Ni content. The fitting results are plotted in Figure $\mathrm{S} 9$ and summarized in Table 2. The portion of $\mathrm{Ni}^{n+}{ }_{\text {oct }}$ reduced to $\mathrm{Ni}^{0}$ at $600{ }^{\circ} \mathrm{C}$ increased from $35 \%$ in LFNO-5Ni to approximately $50 \%$ in LFNO-20Ni (Table 2). This trend complements the shift of the XRD data shown in Figure 1, in which the magnitude of the $2 \theta$ shift after reduction, towards the position of LFO, increased with the increasing Ni content in LFNO. Between 80 and $90 \%$ of the overall $\mathrm{Ni}$ had entered the lattice in all LFNO samples after oxidation at $650^{\circ} \mathrm{C}$ for $1 \mathrm{~h}$. All $\mathrm{Ni}$ was in the $\mathrm{Ni}^{\mathrm{n}+}{ }_{\text {oct }}$ oxidation and coordination state after oxidation for $2 \mathrm{~h}$ in the case of LFNO-20Ni, indicating complete structural reversibility in this sample. From the TPR experiments discussed previously, we assume that this is also valid for all LFNO samples with a lower $\mathrm{Ni}$ content. In the case of $\mathrm{LaNiO}_{3 \pm \delta}$, all $\mathrm{Ni}$ was reduced and a minimum of $68 \%$ was still in the $\mathrm{Ni}^{2+}$ state after reoxidation. On impregnated LFO-20Ni, $85 \% \mathrm{Ni}$ was found as $\mathrm{Ni}^{0}$ after reduction and no $\mathrm{Ni}$ was oxidized to $\mathrm{Ni}^{n+}{ }_{\text {oct }}$ even after long reoxidation at $650^{\circ} \mathrm{C}$.

All of these findings provide evidence for the reversible $\mathrm{Ni}$ segregation and complete reincorporation into a La-Fe-O host lattice. Furthermore, they confirm the absence of incorporation of $\mathrm{Ni}^{2+}$ dispersed in the form of $\mathrm{NiO}$ particles on $\mathrm{LaFeO}_{3}$ and the limited ability of structural restoration at moderate temperatures $\left(<650^{\circ} \mathrm{C}\right)$.

\section{Electron microscopy}

We used scanning electron microscopy (SEM) to demonstrate another important function induced by the structural reversibility of LFNO: the stabilization of the $\mathrm{Ni}$ particle size (Figure 5). After reduction at $600^{\circ} \mathrm{C}$, particles with a diameter in the range of $5-30 \mathrm{~nm}$ appeared on the surface of LFNO20Ni crystallites (Figure 5 b), which were not visible on the calcined material (Figure $5 \mathrm{a}$ ). Despite the weak $Z$ contrast of the electron image, higher average $Z$ elements could be identified in these particles, which is an indication for their metallic nature. Further analysis using scanning transmission electron microscopy (STEM) coupled with energy-dispersive X-ray spectroscopy (EDX) confirmed the dominant $\mathrm{Ni}$ agglomerations in these particles (Figure $5 \mathrm{e}$ ) whereas both La (Figure $5 \mathrm{f}$ ) and Fe (Figure $5 \mathrm{~g}$ ) remained uniformly distributed across the material after reduction. The formation of $\mathrm{La}_{2} \mathrm{O}_{3}$ upon reduction, which was observed by using XRD, could not be confirmed using SEM or STEM. This is most likely because of $\mathrm{La}_{2} \mathrm{O}_{3}$ formation at the invisible grain boundaries in the bulk of the sample and/or because of the small size and the low number of $\mathrm{La}_{2} \mathrm{O}_{3}$ crystallites on the imaged surface. $\mathrm{Ni}$ particles completely disappeared after reoxidation (Figure $5 \mathrm{c}$ ), which can be attributed to $\mathrm{Ni}$ incorporation in agreement with the above evidence and discussion.

Irrespective of the mechanism, if $\mathrm{Ni}$ is incorporated inside a LFNO host lattice it can segregate reversibly from and be completely reincorporated into the perovskite lattice in a fashion similar to the self-regeneration properties claimed for precious metals. ${ }^{[3]}$ We have demonstrated that this property de- 


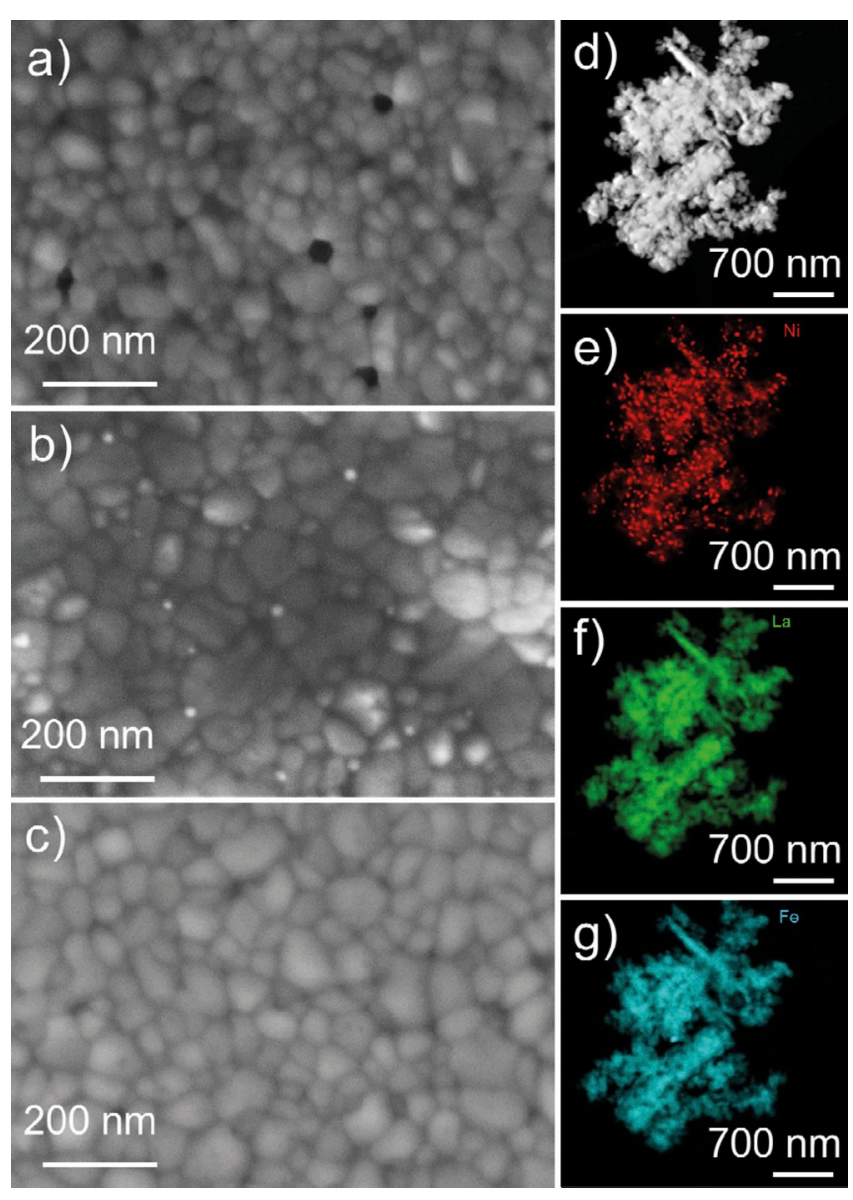

Figure 5. SEM images of LFNO-20Ni: a) calcined, b) reduced (10 vol $\% \mathrm{H}_{2}$, $\left.600^{\circ} \mathrm{C}, 1 \mathrm{~h}\right)$, and c) reoxidized ( $\left.20 \mathrm{vol} \% \mathrm{O}_{2}, 650^{\circ} \mathrm{C}, 2 \mathrm{~h}\right)$. d) STEM image of reduced LFNO-20Ni and the corresponding EDX compositional analysis data for e) Ni, f) La, and g) Fe.

pends strongly on the selected temperature range also in the case of $\mathrm{Ni}$. The potential benefit is highlighted in the SEM images of LFNO-20 after a single reduction and after reduction in five redox cycles (Figure $6 \mathrm{a}$ and b). SEM images of the impregnated sample LFO-20Ni after the same treatment are shown in Figure $6 \mathrm{c}$ and $\mathrm{d}$. No apparent difference was visible in the $\mathrm{Ni}$ average particle size and particle density between the two states in the case of LFNO-20Ni. In contrast, both of these values were significantly influenced by the number of redox cycles in the case of LFO-20Ni. This difference is quantified in Figure $6 \mathrm{e}$, in which particle size distributions obtained from the SEM images of LFO-20Ni and LFNO-20Ni are compared. After a single reduction, the $\mathrm{Ni}$ particle size was more centered at $10-15 \mathrm{~nm}$ in the case of LFNO-20Ni and was only slightly affected by redox cycling. The particle size distribution of LFO-20Ni was broader after the first reduction and it was further broadened and shifted towards larger sizes after five redox cycles, which evidences $\mathrm{Ni}$ sintering clearly. Sintering was also confirmed by the evolution of the mean particle sizes and the particle surface density shown in Figure $6 \mathrm{f}$. The mean particle size of LFNO-20Ni increased only within the standard error of the measurement, whereas it increased significantly in the case of LFO-20Ni and was accompanied by a decrease of the particle density from approximately $400 \mu \mathrm{m}^{-2}$ to below $200 \mu \mathrm{m}^{-2}$. LFNO-20Ni demonstrated the opposite behavior, and the surface density of the Ni particles increased with increasing redox cycling. This behavior can be explained by the slow segregation kinetics of $\mathrm{Ni}$ through the perovskite lattice or the initial presence of Ni particles at the grain boundaries of perovskite crystallites. Ni can be further mobilized with each redox cycle and segregates to free surfaces, where it not only contributes to the observed $\mathrm{Ni}$ particle surface density but is also potentially accessible for catalytic reactions.

\section{$\mathrm{CO}_{2}$ hydrogenation}

The potential of the reversible segregation-incorporation of $\mathrm{Ni}$ and the protective function of $\mathrm{LaFeO}_{3}$ towards $\mathrm{Ni}$ particle growth were tested for the catalytic activity and stability towards $\mathrm{CO}_{2}$ hydrogenation as the probe reaction. The $\mathrm{CO}_{2}$ conversion profiles of LFNO-20Ni, LFO-20Ni, and $5 \mathrm{wt} \% \mathrm{Ni} / \mathrm{Al}_{2} \mathrm{O}_{3}$ pre-reduced and after a number of redox cycles are presented in Figure 7. It is apparent that calcined LFNO-20Ni exhibited the lowest $\mathrm{CO}_{2}$ conversion levels among the three catalysts. From the above characterization methods, it is clear that after reduction LFNO-20Ni displays less catalytically active $\mathrm{Ni}$ than LFO-20Ni at the $\mathrm{LaFeO}_{3}$ surface (Figure $6 \mathrm{f}$ ). We used XAS to show that only $50 \%$ of the overall $\mathrm{Ni}$ was reduced in the case of LFNO-20Ni (compared to $85 \%$ for LFO-20Ni; Table 2) and not all of this fraction may have segregated to the LFNO surface and was available for reaction. ${ }^{[7]}$ Above $550^{\circ} \mathrm{C}$, all catalysts gave rise to equal $\mathrm{CO}_{2}$ conversion indicative of the thermodynamically controlled reaction regime. Notably, the exhaust gas of the two perovskite-based catalysts contained significant amounts of $\mathrm{CO}$ in addition to $\mathrm{CH}_{4}, \mathrm{H}_{2} \mathrm{O}$, and unreacted $\mathrm{CO}_{2}$ and $\mathrm{H}_{2}$ in line with selectivity issues associated with this reaction. ${ }^{[64-66]}$ Only Ni/Al${ }_{2} \mathrm{O}_{3}$ showed a significant $\mathrm{CO}_{2}$ conversion at low temperature $\left(15 \%\right.$ at $\left.300^{\circ} \mathrm{C}\right)$ whereas the same conversion level was attained at 410 and $360^{\circ} \mathrm{C}$ by LFNO and LFO-20Ni, respectively. Of the three catalysts, $\mathrm{Ni} / \mathrm{Al}_{2} \mathrm{O}_{3}$ was by far the most active and attained maximum conversions of approximately $70 \%$ at $440{ }^{\circ} \mathrm{C}$. We associate this high activity primarily to the SSA of $\mathrm{Ni} / \mathrm{Al}_{2} \mathrm{O}_{3}$, which is an order of magnitude larger than that of the perovskite-based catalysts.

The redox behavior of the two impregnated catalysts (Ni/ $\mathrm{Al}_{2} \mathrm{O}_{3}$ and LFO-20Ni) is fundamentally different from that of LFNO-20Ni. The $\mathrm{CO}_{2}$ conversion profiles of this sample relative to its initial performance in the fresh state are shown in Figure 7. The $\mathrm{CO}_{2}$ conversion of LFNO-20Ni improved significantly over the first five cycles after which it remained stable (Figure 7 a). The relative conversion increase was approximately $100 \%$ over five redox cycles (Figure $7 \mathrm{~d}$ ). In contrast to this sample, both impregnated catalysts $\mathrm{Ni} / \mathrm{Al}_{2} \mathrm{O}_{3}$ and LFO-20Ni exhibited negative activity changes over the number of redox cycles (Figure 7e and f). The initial activity increase of LFNO$20 \mathrm{Ni}$ can be explained by similar arguments derived from the observations presented in Figure $6 \mathrm{e}$ and $\mathrm{f}$. The above characterization data demonstrate that an increasing amount of $\mathrm{Ni}$ forms at the surface of LFNO-20Ni with increasing the number 


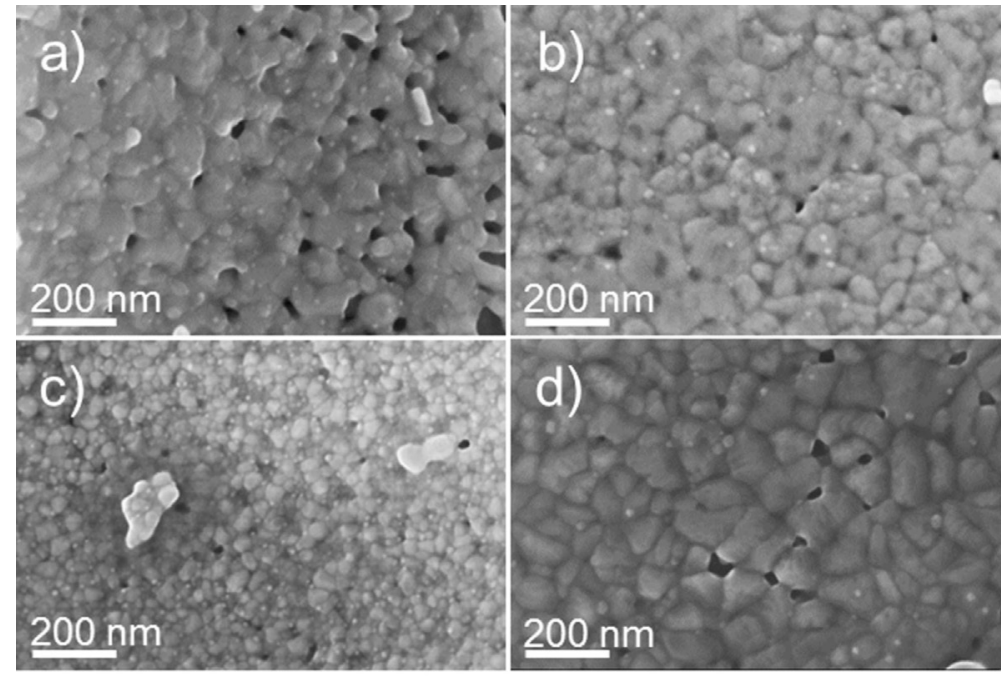

e)

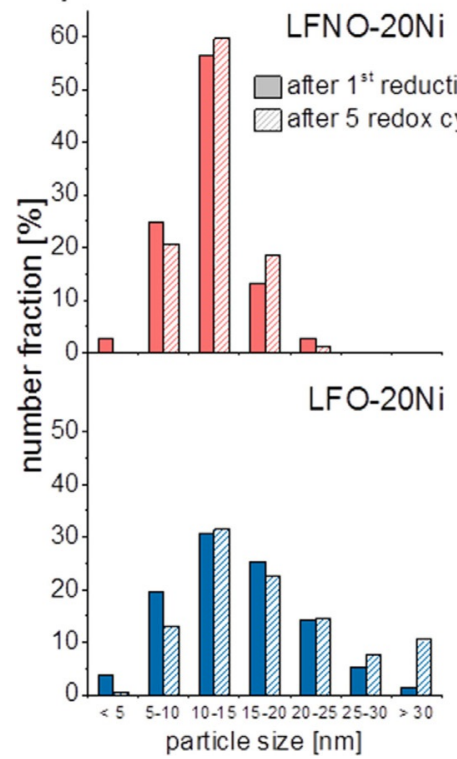

f)

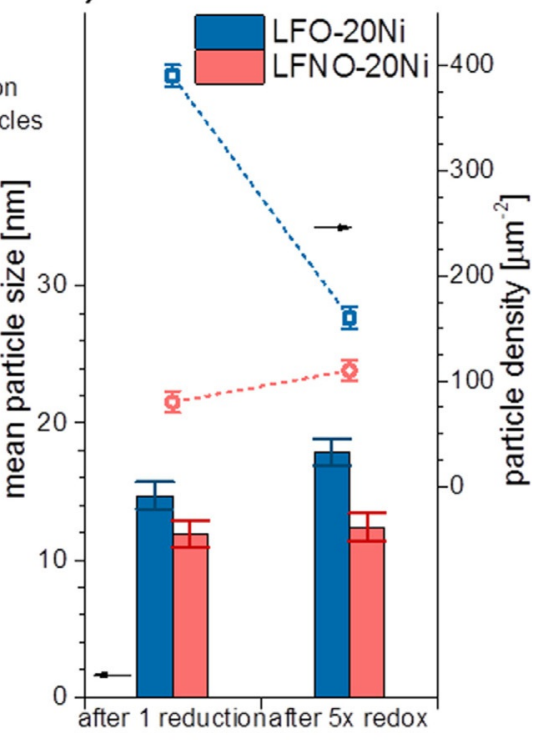

Figure 6. SEM images of a) LFNO-20Ni after a single reduction ( 10 vol $\% \mathrm{H}_{2}, 600^{\circ} \mathrm{C}, 1 \mathrm{~h}$ ) and b) reduced after five redox cycles (reoxidation at 20 vol $\% \mathrm{O}_{2}$, $650^{\circ} \mathrm{C}, 2 \mathrm{~h}$ ), and c) LFO-20Ni after a single reduction and d) reduced after five redox cycles. e) Ni particle size distribution of both samples after single reduction and reduced after five redox cycles. f) Mean Ni particle size and particle densities. Error bars represent standard errors based on estimated uncertainties.

of redox cycles. The catalytic activity of reduced LFNO-20Ni eventually exceeded that of fresh LFO-20Ni likely because of the small mean particle size and narrow size distribution.

\section{Conclusions}

The reversible segregation of $\mathrm{Ni}$ from a $\mathrm{LaFe}_{1-x} \mathrm{Ni}_{x} \mathrm{O}_{3 \pm \delta}$ perovskite-type host lattice was demonstrated using $\mathrm{X}$-ray based methods (XRD, XAS), temperature-programmed reduction, and electron microscopy (SEM, (S)TEM). This process offers the great potential to reverse particle sintering under conditions that are typically applied to regenerate coked catalysts. This can increase both the catalyst lifetime and cost efficiency significantly. $\mathrm{Ni}$ was exclusively reduced at reduction temperatures of $600^{\circ} \mathrm{C}$ and segregated to the oxide surface at which it formed catalytically active $\mathrm{Ni}$ metal particles. Furthermore, the extent of $\mathrm{Ni}$ reduction from the perovskite depended on the perovskite $\mathrm{B}$-site composition and increased from approximately $35 \%$ in $\mathrm{LaFe}_{0.95} \mathrm{Ni}_{0.05} \mathrm{O}_{3 \pm \delta}$ to $50 \%$ in $\mathrm{LaFe}_{0.8} \mathrm{Ni}_{0.2} \mathrm{O}_{3 \pm \delta}$. Full structural reincorporation was achieved after oxidation at $650^{\circ} \mathrm{C}$ for $2 \mathrm{~h}$. Reversible Ni segregation resulted in active and highly redox stable $\mathrm{Ni}$ catalysts. Ni particle growth, which was observed for impregnated samples of the type $\mathrm{Ni} / \mathrm{LaFeO}_{3 \pm \delta}$ and $\mathrm{Ni} / \mathrm{Al}_{2} \mathrm{O}_{3}$, was completely suppressed. Ni particle sintering is well known for $\mathrm{Ni}$ /support catalysts prepared by impregnation methods and the fact that it can be observed on both $\mathrm{LaFeO}_{3}$ and $\mathrm{Al}_{2} \mathrm{O}_{3}$ suggests that the inhibition of this process cannot be attributed to a stabilizing nature of the perovskite surface but indeed only to the reversible reincorporation of $\mathrm{Ni}$ into the perovskite host lattice. 

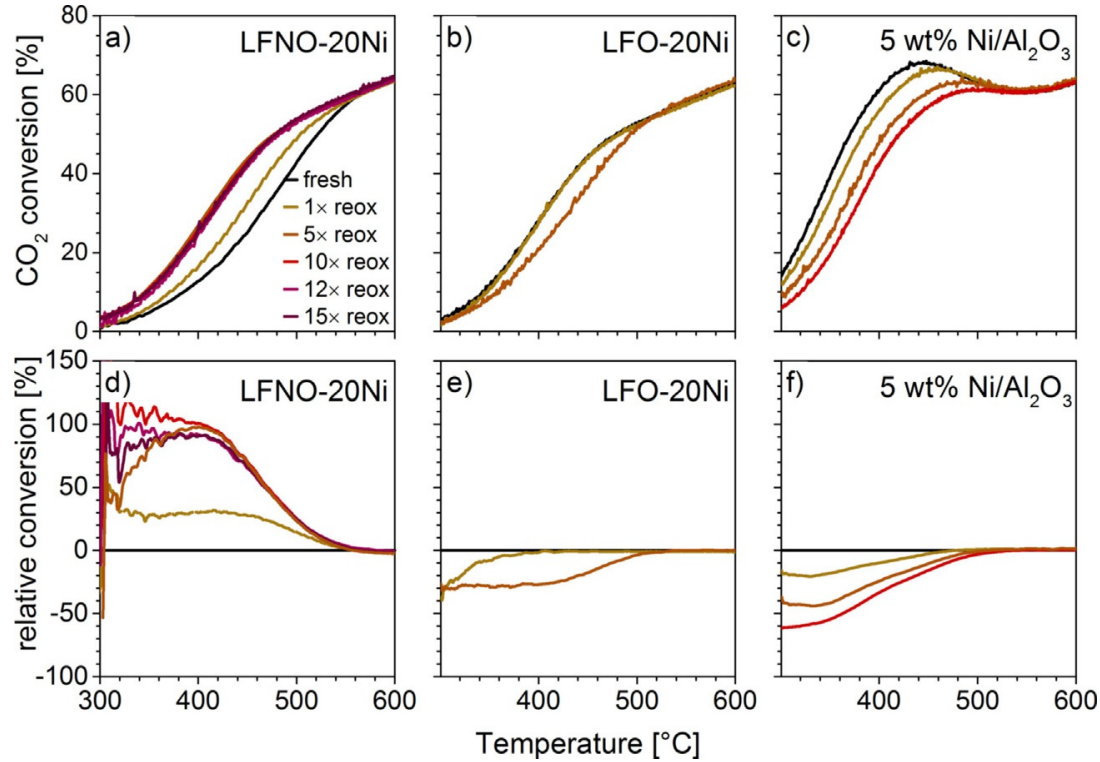

Figure 7. $\mathrm{CO}_{2}$ conversion profiles of a) LFNO-20Ni, b) LFO-20Ni, and c) $5 \mathrm{wt} \% \mathrm{Ni} / \mathrm{Al}_{2} \mathrm{O}_{3}$ over a number of redox $\mathrm{cycles}$. $\mathrm{CO}_{2}$ conversion relative to the initial activity of prereduced material for d) LFNO-20Ni, e) LFO-20Ni, and f) $5 \mathrm{wt} \% \mathrm{Ni} / \mathrm{Al}_{2} \mathrm{O}_{3}$ over the same redox cycles.

\section{Experimental Section}

\section{Materials preparation}

LaFe ${ }_{1-x} \mathrm{Ni}_{x} \mathrm{O}_{3 \pm \delta}$ perovskite-type metal oxides were prepared by an amorphous citrate solution-based process. ${ }^{[67]}$ Suitable amounts of $\mathrm{La}\left(\mathrm{NO}_{3}\right)_{3} \cdot 6 \mathrm{H}_{2} \mathrm{O}$ (Sigma-Aldrich, $99.999 \%$ trace metals basis), $\mathrm{Fe}\left(\mathrm{NO}_{3}\right)_{3} \cdot 9 \mathrm{H}_{2} \mathrm{O}$ (Sigma-Aldrich, $\geq 99.95 \%$ trace metals basis), and $\mathrm{Ni}\left(\mathrm{NO}_{3}\right)_{2} \cdot 6 \mathrm{H}_{2} \mathrm{O}$ (Sigma-Aldrich, $99.999 \%$ trace metals basis) were each dissolved in water and mixed thoroughly before being added to an aqueous solution of citric acid (Sigma-Aldrich, ACS reagent, $\geq 99.5 \%$ ). The overall molar ratio of metal nitrates to citric acid was kept constant at 1:1.05 for all samples. The precursor solution was stirred at $70^{\circ} \mathrm{C}$ for $60 \mathrm{~min}$ before drying for $12 \mathrm{~h}$ at $70^{\circ} \mathrm{C}$ under vacuum. The resultant solid precursor foam was crushed to a fine powder and then subjected to calcination in air at $700^{\circ} \mathrm{C}$ for $2 \mathrm{~h}\left(5^{\circ} \mathrm{C} \mathrm{min}{ }^{-1}\right.$ to $200^{\circ} \mathrm{C}$; then, $10^{\circ} \mathrm{C} \mathrm{min}^{-1}$ to $\left.700^{\circ} \mathrm{C}\right)$. For comparison, $\mathrm{NiO} / \mathrm{LaFeO}_{3 \pm \delta}$ was prepared by the wet impregnation of calcined $\mathrm{LaFeO}_{3 \pm \delta}$ with an aqueous solution of $\mathrm{Ni}\left(\mathrm{NO}_{3}\right)_{2} \cdot 6 \mathrm{H}_{2} \mathrm{O}$ (Sigma-Aldrich, $99.999 \%$ trace metals basis), to achieve 1.2 and $4.8 \mathrm{wt} \% \mathrm{Ni}$, followed by calcination in air at $500^{\circ} \mathrm{C}$ for $2 \mathrm{~h}$. $\mathrm{Ni} / \mathrm{Al}_{2} \mathrm{O}_{3}$ $\left(5 \mathrm{wt} \% ; 135 \mathrm{~m}^{2} \mathrm{~g}^{-1}\right.$ ) was prepared by the wet impregnation of $\gamma$ $\mathrm{Al}_{2} \mathrm{O}_{3}\left(141 \mathrm{~m}^{2} \mathrm{~g}^{-1}\right.$, Sasol) with an aqueous solution of $\mathrm{Ni}\left(\mathrm{NO}_{3}\right)_{2} \cdot 6 \mathrm{H}_{2} \mathrm{O}$ (Merck, pro analysis). Drying at $90^{\circ} \mathrm{C}$ overnight was followed by calcination in air at $550^{\circ} \mathrm{C}$ for $4 \mathrm{~h}$. A list of samples and their denotations is provided in Table 1.

\section{Characterization}

The specific surface area (SSA) of the calcined powders was determined from the $\mathrm{N}_{2}$-adsorption isotherms at $-196^{\circ} \mathrm{C}$ according to the BET model using a Quantachrome Autosorb I instrument. Before the SSA determination the samples were treated under vacuum at $300^{\circ} \mathrm{C}$ for $2 \mathrm{~h}$.

The powder composition was verified on acid-digested samples by using ICP-MS (Agilent 7700x) with dilution factors of $2 \times 10^{7}$ for La and Fe quantifications and of $10^{6}$ for Ni quantification.
The crystal structure of calcined, reduced $\left(10\right.$ vol $\left.\% \mathrm{H}_{2}, 600^{\circ} \mathrm{C}, 1 \mathrm{~h}\right)$, and reoxidized powders $\left(20 \mathrm{vol} \% \mathrm{O}_{2}, 650^{\circ} \mathrm{C}, 2 \mathrm{~h}\right)$ was investigated by using ex situ powder X-ray diffraction (XRD; Bruker D8 Advance) equipped with Ni-filtered Cu radiation, variable slits and an energysensitive line detector (LynxEye). Diffractograms were collected at an acquisition time of $4 \mathrm{~s}$ and a step size of $\Delta 2 \theta=0.03^{\circ}$ between $2 \theta=15$ and $80^{\circ}$. Before XRD analysis, reduction and reoxidation were performed in the same heated tubular quartz reactor used for the catalytic study.

Temperature-programmed reduction (TPR) experiments were conducted on calcined powder samples using a bench-top TPDRO1100 (ThermoElectron) instrument equipped with mass flow controllers and a thermal conductivity detector. The samples $(100 \mathrm{mg})$ were loaded into the quartz reactor tube and heated under a constant flow of $20 \mathrm{vol} \% \mathrm{O}_{2}$ to $500^{\circ} \mathrm{C}$ to clean the sample surface. After cooling to RT, the TPR was started in $20 \mathrm{~mL} \mathrm{~min}^{-1} 10 \mathrm{vol} \% \mathrm{H}_{2}$ / $\mathrm{Ar}$ at STP with a heating ramp of $5^{\circ} \mathrm{Cmin}^{-1}$. TPR redox experiments were conducted to estimate the reoxidation temperature at which $\mathrm{Ni}$ is reincorporated reversibly into the perovskite lattice. The first TPR of the calcined sample was collected up to $600^{\circ} \mathrm{C}$ followed by reduction at this temperature for $1 \mathrm{~h}$. The sample was then cooled in $\mathrm{Ar}$ to $\mathrm{RT}\left(25^{\circ} \mathrm{C}\right)$ before reoxidation in $20 \mathrm{vol} \% \mathrm{O}_{2} / \mathrm{N}_{2}$ at $500^{\circ} \mathrm{C}$ for $2 \mathrm{~h}$. The sample was again cooled in $\mathrm{Ar}$ to $25^{\circ} \mathrm{C}$, and the second TPR was started on the reoxidized material. TPR-reduction-reoxidation-TPR cycles were repeated three times. The reoxidation temperatures were set to 500,600 , and $700^{\circ} \mathrm{C}$ and did not exceed the initial calcination temperature. The heating rate during reoxidation and cooling after all experiments was $10^{\circ} \mathrm{Cmin}^{-1}$.

Ni K-edge ( $8.333 \mathrm{keV})$ X-ray absorption spectra were acquired at the X10DA (SuperXAS) beamline at the Swiss Synchrotron Light Source (SLS, Villigen, Switzerland). The beam current and the energy of the storage ring were $400 \mathrm{~mA}$ and $2.4 \mathrm{GeV}$, respectively. Spectra were collected in fluorescence mode using an ion chamber filled with $\mathrm{He} / \mathrm{N}_{2}$ to measure the incoming beam intensity and a five-element SD silicon drift detector mounted at $90^{\circ}$ to the beam and the sample mounted at $45^{\circ}$. The beam was collimated with a Si-coated mirror, which was also used for the reduction of 
higher harmonic contributions, and the required X-ray energies were scanned around the $\mathrm{Ni}$ absorption edge using a $\mathrm{Si}(111)$ channel-cut monochromator. The beam was focused to a spot size of $2 \mathrm{~mm} \times 0.2 \mathrm{~mm}(H \times V)$. Ex situ measurements of reference materials were performed on pelletized samples. In situ experiments were conducted on powder samples (100-150 $\mu \mathrm{m}$ sieve fraction) sandwiched between two quartz wool plugs in quartz capillary reactors $(\varnothing=3 \mathrm{~mm}, 50 \mu \mathrm{m}$ wall thickness; Hilgenberg). The total flow rate of the feed gas was kept constant at $50 \mathrm{~mL} \mathrm{~min}^{-1}$ at STP. Samples were heated in $20 \mathrm{vol} \% \mathrm{O}_{2} / \mathrm{Ar}$ to $600^{\circ} \mathrm{C}$ using an air blower (LEmini, $800 \mathrm{~W}$ ). The sample temperature was measured by using a K-type thermocouple placed in the middle of the catalyst bed. EXAFS spectra of the calcined state was recorded in $\mathrm{O}_{2} / \mathrm{Ar}$ at $600^{\circ} \mathrm{C}$. Samples were then reduced in 10 vol $\% \mathrm{H}_{2} / \mathrm{Ar}$ at $600^{\circ} \mathrm{C}$ for $1 \mathrm{~h}$ before collecting the full EXAFS spectrum of the reduced state. The subsequent reoxidation was conducted in $20 \mathrm{vol} \% \mathrm{O}_{2} / \mathrm{Ar}$ at $650^{\circ} \mathrm{C}$ for $1 \mathrm{~h}$ before the EXAFS spectrum was collected of the reoxidized state. The Demeter software package (version 0.9.24 $4^{[68]}$ ) was used to reduce and model all data. The pseudoradial distribution functions $(R)$ were obtained by Fourier transforming $k^{3}$-weighted $k$-functions typically in the range of $2.0-12.0 \AA^{-1}$ using a Hanning window function. The fitting of $R$ was generally performed in the range of $1.0-4.0 \AA$. Nickel(II) oxide (black), a nickel metal foil, $\mathrm{LaNiO}_{3}$, and impregnated $\mathrm{LaFeO}_{3}$ were used as reference compounds. For this purpose, $\mathrm{LaNiO}_{3}$ was prepared by the citric acid method as described above and calcined at $900^{\circ} \mathrm{C}$ for $5 \mathrm{~h}$ to yield the required phase purity. $\mathrm{NiO}$ was produced by the calcination of $\mathrm{Ni}\left(\mathrm{NO}_{3}\right)_{2} \cdot 6 \mathrm{H}_{2} \mathrm{O}$ (Sigma-Aldrich, $99.999 \%$ ) at $500^{\circ} \mathrm{C}$ for $2 \mathrm{~h}$. The $\mathrm{LaFeO}_{3}$ structure $(\mathrm{Pnma}$ ) was taken to fit $\mathrm{R}$ of $\mathrm{Ni}$ in the coordination state of $\mathrm{Fe}$ in partially substituted $\mathrm{LaFe}_{1-x} \mathrm{Ni}_{x} \mathrm{O}_{3 \pm \delta}$. Therefore, the central $\mathrm{Fe}$ ion was replaced by $\mathrm{Ni}$ in the structure file, which is a valid assumption because both structures exhibit the orthorhombic crystal symmetry (vide infra) and because of the similar ionic radii of $\mathrm{Fe}^{3+}(64.5 \mathrm{pm})$ and $\mathrm{Ni}^{3+}(60 \mathrm{pm})$ in an octahedral coordination. The parameters used for the fitting are the coordination number $\left(N_{\mathrm{i}}\right)$, the mean square disorder $\left(\sigma_{\mathrm{i}}^{2}\right)$, and the bond distance $\left(R_{\mathrm{i}}\right)$.

Linear combination fits (LCF) of XANES spectra were performed in the spectral range $-20 \mathrm{eV}<E_{0}<30 \mathrm{eV}$ around the absorption edge to quantify the fraction of each $\mathrm{Ni}$ species present in the samples. Reference compounds for each fit included the Ni foil, $4.8 \mathrm{wt} \% \mathrm{Ni}$ on $\mathrm{LaFeO}_{3}(\mathrm{LFO}-20 \mathrm{Ni})$, and the corresponding incorporated material (LFNO) in its calcined state.

Changes in the microstructure of the samples as a result of repeated redox cycles were studied using field-emission SEM (Zeiss ULTRA 55). Calcined and pretreated powder samples were spread on sticky carbon pads and mounted on Al stubs before analysis. The samples were analyzed with a $10 \mathrm{keV}$ electron beam and the in-lens secondary electron detector at a working distance of $8.0 \mathrm{~mm}$. Typical magnifications in the range of 50000-100000 allowed the analysis of $\mathrm{Ni}$ particles of a minimum size of $5-10 \mathrm{~nm}$.

Scanning transmission electron microscopy (STEM) images were collected using an analytical TEM (FEI Talos F200X) equipped with a Super-X EDX system (windowless) and a HAADF detector. The accelerating voltage was set to $200 \mathrm{kV}$. EDX maps $(512 \times 512$ pixels) were acquired at a resolution of $7 \mathrm{~nm}$.

\section{Catalytic activity}

Catalytic activity tests towards $\mathrm{CO}_{2}$ hydrogenation were performed using a homemade test setup in a quartz reactor in a plug-flow geometry $(6 \mathrm{~mm}$ ID). Mass flow controllers were used to dose the re- actant gases, and a thermocouple placed in the middle of the catalyst bed was used to determine catalyst bed temperature. To avoid back pressure all calcined powders were pelletized (4 MPa), crushed, and sieved to $100-150 \mu \mathrm{m}$ before use. The catalyst (100 mg) was diluted with cordierite powder (100 mg, 75-100 $\mu \mathrm{m}$ ) to achieve a thoroughly mixed catalyst bed of $15 \mathrm{~mm}$ in length. The reactant gas that contained $8 \mathrm{vol} \% \mathrm{CO}_{2}, 32 \mathrm{vol} \% \mathrm{H}_{2}$, and $60 \mathrm{vol} \% \mathrm{Ar}$ was fed at a total flow rate of $50 \mathrm{~mL} \mathrm{~min}^{-1}$ at STP to result in a catalyst load of $30^{\prime} 000 \mathrm{~cm}^{3} \mathrm{~g}^{-1} \mathrm{~h}^{-1}$. Catalytic tests were conducted on prereduced samples $\left(10\right.$ vol $\left.\% \mathrm{H}_{2}, 600^{\circ} \mathrm{C}, 1 \mathrm{~h}\right)$. The experiment was started at $600^{\circ} \mathrm{C}$ under the reaction conditions. The catalyst was left to equilibrate for $10 \mathrm{~min}$ before cooling to $300^{\circ} \mathrm{C}$ at $5^{\circ} \mathrm{Cmin}^{-1}$. All gas lines were made of stainless steel and heated to $120^{\circ} \mathrm{C}$ to avoid condensation. A Pfeiffer OmniStar GSD 320 quadrupole mass spectrometer equipped with a heated stainless-steel capillary was used to analyze the exhaust gas. The $\mathrm{CO}_{2}$ conversion $\left(\mathrm{XO}_{\mathrm{CO}_{2}}\right)$ was determined according to Equation (1) in which $\left[\mathrm{CO}_{2}\right]_{\text {in }}$ and $\left[\mathrm{CO}_{2}\right]_{\text {out }}$ are the initial and final $\mathrm{CO}_{2}$ concentrations, respectively.

$X_{\mathrm{CO}_{2}}[\%]=100 \cdot \frac{\left[\mathrm{CO}_{2}\right]_{\text {in }}-\left[\mathrm{CO}_{2}\right]_{\text {out }}}{\left[\mathrm{CO}_{2}\right]_{\text {in }}}$

Accurate measurements of $\mathrm{Ni}$ surface area and dispersion were not successful because of the low surface area common for perovskitetype materials. Furthermore, the amount of accessible Ni cannot simply be estimated for these materials using average particle sizes and reduction data as reduced $\mathrm{Ni}$ might not have all segregated to the PMO surface. Such estimates are only valid for impregnated materials in which the amount of $\mathrm{Ni}$ on the surface is known. ${ }^{[69]}$ Under these circumstances catalytic activities are not expressed in terms of turnover frequencies. Emphasis in the discussion of the results was laid on the comparison of the redox stability of the various catalysts.

\section{Acknowledgements}

The authors kindly acknowledge the financial support from the Swiss National Science Foundation (SNF, No. 200021_159568), the Swiss Federal Office of Energy (SFOE, SI 501130-01), and the Competence Center for Energy and Mobility (CCEM). Dr. A. Kampolis is kindly acknowledged for providing the $\mathrm{Ni} / \mathrm{Al}_{2} \mathrm{O}_{3}$ catalyst. The work was conducted in the context of the Swiss Competence Center for Energy Research (SCCER BIOSWEET). The Swiss Light Source is thanked for the provision of beam time at the SuperXAS beamline.

Keywords: $\mathrm{CO}_{2}$ hydrogenation - particles $\cdot$ perovskite phase structural reversibility $\cdot$ supported catalysts

[1] S. Royer, D. Duprez, F. Can, X. Courtois, C. Batiot-Dupeyrat, S. Laassiri, H. Alamdari, Chem. Rev. 2014, 114, $10292-10368$.

[2] M. A. Peña, J. L. G. Fierro, Chem. Rev. 2001, 101, 1981-2017.

[3] M. Uenishi, M. Taniguchi, H. Tanaka, M. Kimura, Y. Nishihata, J. Mizuki, T. Kobayashi, Appl. Catal. B 2005, 57, 267-273.

[4] Y. Nishihata, J. Mizuki, T. Akao, H. Tanaka, M. Uenishi, M. Kimura, T. Okamoto, N. Hamada, Nature 2002, 418, 164-167.

[5] H. Tanaka, M. Uenishi, M. Taniguchi, I. Tan, K. Narita, M. Kimura, K. Kaneko, Y. Nishihata, J. Mizuki, Catal. Today 2006, 117, 321 - 328.

[6] I. Hamada, A. Uozumi, Y. Morikawa, A. Yanase, H. Katayama-Yoshida, J. Am. Chem. Soc. 2011, 133, 18506-18509. 
[7] M. B. Katz, G. W. Graham, Y. W. Duan, H. Liu, C. Adamo, D. G. Schlom, X. Q. Pan, J. Am. Chem. Soc. 2011, 133, 18090-18093.

[8] A. Eyssler, A. Winkler, O. Safonova, M. Nachtegaal, S. K. Matam, P. Hug, A. Weidenkaff, D. Ferri, Chem. Mater. 2012, 24, 1864-1875.

[9] Y. Lu, A. Eyssler, E. H. Otal, S. K. Matam, O. Brunko, A. Weidenkaff, D Ferri, Catal. Today 2013, 208, 42-47.

[10] H. Tanaka, M. Taniguchi, N. Kajita, M. Uenishi, I. Tan, N. Sato, K. Narita, M. Kimura, Top. Catal. 2004, 30, 389-396.

[11] D. Fino, N. Russo, G. Saracco, V. Specchia, Prog. Solid State Chem. 2007, 35, $501-511$.

[12] Y. Lu, S. Keav, A. E. Maegli, A. Weidenkaff, D. Ferri, Top. Catal. 2015, 58, 910-918.

[13] J. L. Rogers, M. C. Mangarella, A. D. D'Amico, J.R. Gallagher, M. R. Dutzer, E. Stavitski, J. T. Miller, C. Sievers, ACS Catal. 2016, 6, 5873-5886.

[14] P. Gronchi, D. Fumagalli, R. Del Rosso, P. Centola, J. Therm. Anal. Calorim. 1996, 47, 227-234.

[15] J. R. Rostrup-Nielsen, J. Catal. 1973, 31, 173-199.

[16] J. G. Xu, G. F. Froment, AIChE J. 1989, 35, 88-96.

[17] J. Deng, M. D. Cai, W. J. Sun, X. M. Liao, W. Chu, X. S. Zhao, ChemSusChem 2013, 6, $2061-2065$.

[18] P. Schoubye, J. Catal. 1969, 14, 238-246.

[19] M. Araki, V. Ponec, J. Catal. 1976, 44, 439-448.

[20] J. L. Falconer, A. E. Zagli, J. Catal. 1980, 62, 280-285.

[21] G. Garbarino, D. Bellotti, P. Riani, L. Magistri, G. Busca, Int. J. Hydrogen Energy 2015, 40, 9171 -9182.

[22] Y. T. Shah, A. J. Perrotta, Ind. Eng. Chem. Prod. Res. Dev. 1976, 15, $123-$ 130.

[23] C. H. Bartholomew, Chem. Eng. 1984, 91, 96-112.

[24] Catalytic Hydrotreating in Petroleum Refining: D. C. McCulloch in Applied Industrial Catalysis, Vol. 1, (Ed.: B. R. Leach), Academic Press, New York, 1983, pp. 69-121.

[25] J. W. Fulton, Chem. Eng. 1988, 95, $111-114$.

[26] D. L. Li, Y. Nakagawa, K. Tomishige, Appl. Catal. A 2011, 408, 1-24.

[27] X. L. Pan, X. H. Bao, Acc. Chem. Res. 2011, 44, 553-562.

[28] K. Takehira, T. Shishido, P. Wang, T. Kosaka, K. Takaki, J. Catal. 2004, 221, $43-54$.

[29] S. B. Wang, G. Q. M. Lu, Appl. Catal. B 1998, 16, 269-277.

[30] G. S. Gallego, F. Mondragon, J. Barrault, J. M. Tatibouet, C. Batiot-Dupeyrat, Appl. Catal. A 2006, 311, 164-171.

[31] C. Batiot-Dupeyrat, G. A. S. Gallego, F. Mondragon, J. Barrault, J. M. Tatibouet, Catal. Today 2005, 107-108, 474-480.

[32] T. Jardiel, M. T. Caldes, F. Moser, J. Hamon, G. Gauthier, O. Joubert, Solid State lonics 2010, 181, 894-901.

[33] C. Arrivé, T. Delahaye, O. Joubert, G. Gauthier, J. Power Sources 2013, $223,341-348$.

[34] T.-S. Oh, E. K. Rahani, D. Neagu, J. T. S. Irvine, V. B. Shenoy, R. J. Gorte, J. M. Vohs, J. Phys. Chem. Lett. 2015, 6, 5106-5110.

[35] X. Song, X. Dong, S. Yin, M. Wang, M. Li, H. Wang, Appl. Catal. A 2016, $526,132-138$

[36] D. Neagu, T. S. Oh, D. N. Miller, H. Menard, S. M. Bukhari, S. R. Gamble, R. J. Gorte, J. M. Vohs, J. T. S. Irvine, Nat. Commun. 2015, 6, 8120

[37] D. Burnat, R. Kontic, L. Holzer, P. Steiger, D. Ferri, A. Heel, J. Mater. Chem. A 2016, 4, 11939-11948.

[38] J. Kuc, Y. C. Zhang, R. Erni, S. Yoon, L. Karvonen, A. Weidenkaff, S. K. Matam, Phys. Status Solidi RRL 2015, 9, 282-287.
[39] A. Jahangiri, H. Aghabozorg, H. Pahlauanzadeh, Int. J. Hydrogen Energy 2013, 38, 10407-10416.

[40] H. Wang, Y. Z. Fang, Y. Liu, X. Bai, J. Nat. Gas Chem. 2012, 21, 745-752.

[41] A. Eyssler, P. Mandaliev, A. Winkler, P. Hug, O. Safonova, R. Figi, A. Weidenkaff, D. Ferri, J. Phys. Chem. C 2010, 114, 4584-4594.

[42] D. Ferri, L. Forni, Appl. Catal. B 1998, 16, 119-126.

[43] H. Provendier, C. Petit, J. L. Schmitt, A. Kiennemann, C. Chaumont, J. Mater. Sci. 1999, 34, $4121-4127$.

[44] R. D. Shannon, C. T. Prewitt, J. Inorg. Nucl. Chem. 1970, 32, 1427-1441.

[45] V. V. Kharton, A. P. Viskup, E. N. Naumovich, V. N. Tikhonovich, Mater Res. Bull. 1999, 34, $1311-1317$.

[46] E. A. Kiselev, V. A. Cherepanov, J. Solid State Chem. 2010, 183, 1992 1997.

[47] P. Scherrer, Goettinger Nachrichten 1918, 2, 98.

[48] E. Bontempi, C. Garzella, S. Valetti, L. E. Depero, J. Eur. Ceram. Soc. 2003, 23, 2135-2142.

[49] S. L. Chen, H. L. Zhang, J. Hu, C. Contescu, J. A. Schwarz, Appl. Catal. 1991, 73, 289-312.

[50] J. T. Richardson, M. V. Twigg, Appl. Catal. A 1998, 167, 57-64.

[51] Y. Peng, W. Z. Si, J. M. Luo, W. K. Su, H. Z. Chang, J. H. Li, J. M. Hao, J. Crittenden, Environ. Sci. Technol. 2016, 50, 6442-6448.

[52] Q. W. Zhang, F. Saito, J. Mater. Sci. 2001, 36, 2287-2290.

[53] M. Crespin, P. Levitz, L. Gatineau, J. Chem. Soc. Faraday Trans. 2 1983, 79, $1181-1194$.

[54] S. N. Ruddlesden, P. Popper, Acta Crystallogr. 1957, 10, 538-540.

[55] T. Nakamura, G. Petzow, L. J. Gauckler, Mater. Res. Bull. 1979, 14, 649659.

[56] A. Rabenau, P. Eckerlin, Acta Crystallogr. 1958, 11, 304-306.

[57] M. J. Koponen, M. Suvanto, K. Kallinen, T. J. J. Kinnunen, M. Harkonen, T. A. Pakkanen, Solid State Sci. 2006, 8, 450-456.

[58] J. H. Cheng, A. Navrotsky, X. D. Zhou, H. U. Anderson, J. Mater. Res. 2005, 20, $191-200$.

[59] R. Haugsrud, Corros. Sci. 2003, 45, 211-235.

[60] A. Anspoks, A. Kuzmin, J. Non-Cryst. Solids 2011, 357, 2604-2610.

[61] V. Kumar, R. Kumar, D. K. Shukla, S. Gautam, K. H. Chae, R. Kumar, J. Appl. Phys. 2013, 114, 073704.

[62] M. Idrees, M. Nadeem, N. E. Sung, T. Asanova, T. J. Shin, Chem. Phys. Lett. 2014, 612, 262- 265.

[63] M. C. Sanchez, J. Garcia, J. Blasco, G. Subias, J. Perez-Cacho, Phys. Rev. B 2002, 65, 144409.

[64] G. A. Mills, F. W. Steffgen, Catal. Rev. 1974, 8, 159-210.

[65] S. Rönsch, J. Schneider, S. Matthischke, M. Schluter, M. Gotz, J. Lefebvre, P. Prabhakaran, S. Bajohr, Fuel 2016, 166, 276-296.

[66] J. H. Kwak, L. Kovarik, J. Szanyi, ACS Catal. 2013, 3, 2449-2455.

[67] C. Marcilly, P. Courty, B. Delmon, J. Am. Ceram. Soc. 1970, 53, 56-57.

[68] B. Ravel, M. Newville, J. Synchrotron Radiat. 2005, 12, 537-541.

[69] R. Thalinger, M. Gocyla, M. Heggen, R. Duhin-Borkowski, M. Grunbacher, M. Stoger-Pollach, D. Schmidmair, B. Klotzer, S. Penner, J. Catal. 2016, $337,26-35$.

Manuscript received: February 25, 2017

Revised manuscript received: March 20, 2017

Accepted manuscript online: March 24, 2017

Version of record online: May 11, 2017 